\title{
Modular structure of web-based decision support systems for integrated pest management. A review
}

\author{
Petros Damos ${ }^{1,2}$
}

Accepted: 1 June 2015 / Published online: 2 July 2015

(C) INRA and Springer-Verlag France 2015

\begin{abstract}
Sustainable pest management implies less pesticide use and replacement by safe control alternatives. This requires decision support for rational pest management. However, in practice, successful decision making is dependent upon the availability of integrated, high-quality information. Computer-aided forecasting and related decision support systems make pest control more sustainable by avoiding unwanted consequences of pesticide applications. Here, I review integrated pest management for web-based decision support systems. The major points are the following: (1) Principles of integrated pest management are compatible with sustainable agriculture. (2) Pest models serve as basis of decision making because they offer means to predict the exact time of pest phenological development and initiate management actions. Most models are climate driven. (3) New hardware technology has permitted the registration of automatically recorded climatic data. This data can be combined with pest models through logical operations and forecasting algorithms to develop a software of pest management. (4) Dynamic web interfaces can serve as decision support systems providing the user with real-time pest warnings and recommendations for management actions. (5) Ontology web programing and semantic knowledge representations provide a way to classify and describe agrodata to facilitate information sharing and
\end{abstract}

Petros Damos

damos@agro.auth.gr; petrosdamos@gmail.com

1 Laboratory of Applied Zoology and Parasitology, Department of Crop Production (Field Crops and Ecology, Horticulture and Viticulture and Plant Protection), Faculty of Agriculture, Aristotle University of Thessaloniki, Thessaloniki, Greece

2 Web Science, Mathematics Department, Faculty of Sciences, Aristotle University of Thessaloniki, Thessaloniki, Greece data exploitation over distributed systems. (6) Most available pest management data is published on static web pages and, thus, cannot be classified as decision support systems. Some web-based decision support systems provide user-interactive content and real-time pest forecasts and management support.

Keywords Sustainable pest management $\cdot$ Pest and disease modeling $\cdot$ Expert systems $\cdot$ www $\cdot$ Linked data $\cdot$ Ontology . Computer-based pest forecasting

$\begin{array}{ll}\text { Abbreviations } & \\ \text { AGROVOC } & \text { Agro-vocabulary } \\ \text { AI } & \text { Artificial intelligence } \\ \text { AOS } & \text { Advanced ontology service } \\ \text { DMSS } & \text { Data management system software } \\ \text { DSS } & \text { Decision support system } \\ \text { FAOSTAT } & \text { Food and Agricultural Organisation of the } \\ & \text { United Nations Statistics Division } \\ \text { 4G } & \text { 4th Generation } \\ \text { GIS } & \text { Geographical information systems } \\ \text { ICP } & \text { Integrated crop production } \\ \text { IFP } & \text { Integrated fruit production } \\ \text { IPM } & \text { Integrated pest management } \\ \text { SQL } & \text { Structured query language } \\ \text { OWL } & \text { Ontology web programming } \\ \text { PHP } & \text { Preprocessor hypertext } \\ \text { RDBs } & \text { Relational data bases } \\ \text { RDF } & \text { Resource description framework } \\ \text { SPARQL } & \text { Protocol and RDF query language } \\ \text { Service } & \\ \text { SILK } & \text { Link discovery framework for the web of data } \\ & \text { to set RDF } \\ \text { TXT } & \text { Text files } \\ \text { URI } & \text { Universal resource identifier }\end{array}$




\section{w3C World Wide Web Consortium \\ www World wide web \\ XL Spread sheet application \\ XML Extensible markup language}
Introduction
The significance of integrated pest management for sus- tainable agriculture
What is the role of plant pest and disease models for decision support?
Data processing and forecasting algorithms: modus operandi of computer-aided decision support
Interface of a web-based decision support systems
Ontology web programming: the next generation of web- based decision support?
Instances of web-based decision support for integrated pest management
Challenges and constrains of decision support systems
Vision of the future of decision support system
Conclusion
Acknowledgments
References

\section{Introduction}

The intensification of agricultural production has led to an increase in the use of energy influxes in order to support current needs for food, fiber, and other products (Altieri 1987; Altieri and Nicholls 2000). Especially, pest management relies heavily upon the use of synthetic chemical compounds and related energy influxes. In most cases, the use of nonselective insecticides, and often without any rules, has caused a variety of problems, including environmental degradation, insecticide resistance, negative impacts on natural enemies, and safety for pesticide applicators and the food supply. Fears about these issues have increased the interest in the development of alternative means for pest control that causes trivial or no impact on humans, natural enemies, and the environment (Higley et al. 1986; Dent 1995; Cross and Dickler 1994; Boller et al. 2004). As a result, modern plant protection shifts in reaction to the societal needs and progressively moves in the way of integrated pest management (IPM) and integrated fruit production (Altieri 1987; Cross and Dickler 1994; Altieri and Nicholls 2000; Amano 2001; Lefebvre et al. 2015).

IPM is a decision-based procedure, involving the coordinated use of multiple tactics for optimizing the control of whole categories of pests in an ecologically and economically sound manner. Lately, in 2009, these major IPM principles have been outlined by the European Commission and the European Parliament, giving priority to IPM principles and ecologically safer methods, minimizing the undesirable side effects and use of agrochemicals, to enhance the safeguards to the environment and human health.

Yet, the vast majority of farmers is using empirical derived pest control options, and in many cases, IPM programs are mainly based on pest field monitoring and scheduled management actions. Moreover, although pesticides should be used on a need basis, if alternatives are either nonavailable or noneffective, most IPM programs still rely heavily on them. Recently, the use of biorational compounds, including bioinsecticides, has increased in IPM (Damos 2013a). Nevertheless, all compounds are effective when applied only on particular developmental stages of the target pest.

One additional issue for IPM is the development of reliable decision tools are used which to define accurate application times for pesticides as well as to provide information to select among available control options (Damos and SavopoulouSoultani 2012). Actually, regardless of the available amount of the novel chemical compounds, their choices in IMP are evaluated based on more than one criteria in which application time is indispensable for their success. Therefore, the design and implementation of web-based decision support systems, to enhance IPM programs, makes possible the application of information intensive decision making (Jonew et al. 2010).

For instance, many millions of EU Integrated Fruit Production Orchards that would have received accurate pesticide application are not treated in precise times due to the lack of formal pest information forecast and related decision support systems. Additionally, several guidelines have been set to be adopted by public or private cooperatives, certification systems, and authorities. However, to be applied on a regular basis enables the accesses and exploitation of agronomical information and data that can be mediated only through the implementation of robust decision support systems (DSS). Once established, such systems can be further used to model agroecosystems and to provide decision at the farm level. This may contribute to optimization of regional specific crop productivity and ensure the rational utilization of innate resources and rural sustainability.

Data exploitable in integrated crop production (ICP) and IPM, which are often referred as sustainable crop production and pest management, respectively, may contain different types of agrodata. Particularly, they can include (1) weather records such as temperature, relative humidity, and weather output; (2) biological data, pest population data and disease symptoms; (3) biophysical data such as plant-growing phenological stages; (4) geophysical data like season climate, soils, terrain, and other characteristics; and (5) socioeconomic information which often include farmer survey results and census information, chemical registrations, residual levels of pesticides, commodity prices, and so on (Waheed et al. 2003; Abdullah and Hussain 2006). Yet such kind of information is either not registered for particular areas of interest or 
decentralized and is locally stored in different institutes, governments, and corporation. Furthermore, data are saved under several formats, which do not permit interpretation, exploitation, and availability (Damos and Karabatakis 2013).

Accessibility on information and survey data can be further combined with information technology to develop simple rule-based arrangements on specific agricultural research areas such as plant protection, harvest yield, resource and energy inputs management, and rural economic development (Carlson and Headley 1987). Concerning IPM particularly, information may include pest modeling results to be expanded toward a "decision system" or "decision management tool," which employs a mixture of population and process models, where appropriate/possible, to improve management action (Damos and Karabatakis 2013).

Recently, the fast emergence of the world wide web (www) has radically modified the room we share knowledge by removing the barrier to publishing, accessing, and exploiting data. The properties of the www combined with simple handling of software may be applied to infer potential relevance to users' search queries through web applications. To date, this functionality has been enabled by the generic, open, and extensible nature of the Internet, the www, and the rapid expansion of smart phones (Jacobs and Walsh 2004; d'Aquin et al. 2008).

However, only in the last years, the same principles that enabled the web of documents to flourish have been also applied to publish and manage agrodata. Additionally, using the same framework, such data can be immediately translated to agricultural practice through real-time smart web applications (Damos and Karabatakis 2013). For instance, web-based pest forecasting models and DSS are becoming popular, and it is expected that the demand for such applications will increase more in the future. Actually, decision support system may become an absolute requirement for local, regional/area-wide, as well as of international implementation of IPM systems (Waheed et al. 2003). Figure 1 shows a simple ruled decision finding process, which is based on temperature-driven phenology models and is used as decision tool for precise timing of pest management actions. Based on such processes, highly developed countries have posted interactive web sites, which include real-time weather and market information and geographical information-based systems (GIS) to provide farmers real-time decision support in crop management (Bajwa et al. 2003; Prasad and Prabhabar 2012; and references). Nevertheless, web-based DSS structures, in general, use large amounts of data, which may accrue from multidisciplinary sources. These data are actually placed in a distributed cloud computer environment and deliver the possibility to integrate to support decision making.

In this context, the current work emphasizes on integrated pest management and how it can be incorporated in the modular structure of web-based decision support systems. In

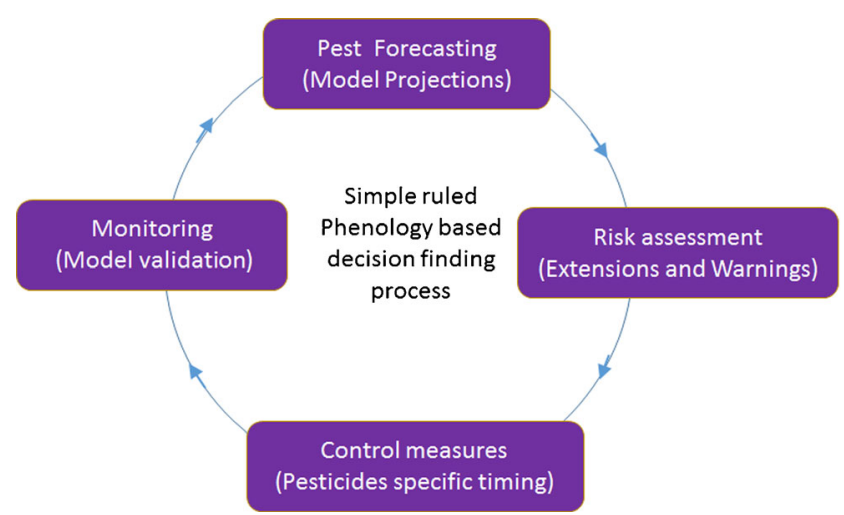

Fig. 1 Simple ruled decision finding process based on phenology models and the importance of precise timing during plant protection. Providing weather data outcome information pest emergence and infection rates, based on pest and disease simulation models. In principle, the systems deal with tables of raw information, often numerical, collated into sums or averages, while the forecasting model uses these data to provide future estimates of the variables of interest (e.g., population dynamics, disease epidemiology)

particular, this article goes over the application of real-time pest forecasting systems through a literature review as basis, researching some related and most representative cases. Moreover, since huge field datasets and pest models serve as basis for decision making in IPM, one of the intentions is to identify critical issues in pest model development and in their inclusion into plant protection decision support systems. Especially, among the objectives were to interpret the role of IPM as an element of sustainable agriculture and to outline the importance of pest models for plant protection and their utility for target specificity to minimize side effects. Additionally, efforts are made to give ways of transforming pest models into a warning system, using simple logical operations and conventions, and to identify the architecture of such systems as well as the utility of knowledge-based organizations. At the last sections, representative examples of web-based decision support systems are reviewed, while some challenges and constrains related to the development and deliverance of information systems are also outlined. Finally, a brief account on the vision of the future of decision support system is made and how it may be affected by the farmer's perspective and technological advances.

\section{The significance of integrated pest management for sustainable agriculture}

Integrated pest management plays an essential role in sustainable agriculture, and in the next section, I provide a brief account on the significance of IPM through a sustainable agriculture perspective. Agricultural ecosystems, or agroecosystems, are basic units of spatial and functional agricultural activity, which include biotic and abiotic components involved and their interactions (Altieri 1987; Dent 1995; 
Altieri and Nicholls 2000; Zhang et al. 2008). Sustainability rests on the principle that agricultural systems need to meet the present demands without comprising the ability of future generations to meet their own needs (Lichtfouse et al. 2009). Traditionally, the productivity of agroecosystems relies heavily on the use of energy influxes, while the sustainability depends on how agroecosystems are managed at the site scale as easily as to the diversity, composition, and functioning of the surrounding landscape and related energy influxes (Tilman 1999; Tilman et al. 2001). To date, the radical intensification in crop production can be summarized as the result of the following actions (Dent 1995; after modification):

- Progressive expansion of subject land

- The use of monoculture as a result of the development of genetic uniform crops

- Growth of high-yielding varieties of cereal grains and distribution of hybridized seeds

- The increase in plant density

- The increase in all kinds of energy influxes such as synthetic fertilizers and pesticides, expansion of irrigation infrastructure, and availability of water planning

- Specialization and mechanization

- Globalization and growth of international exchange in all aspects, for instance, plant material, products, capital

- Improvement of agricultural science

Entirely the same, by depositing with a holistic view, the process of intensification in crop production and the aforementioned actions have also affected pest-plant communities and their management. Hence, current crop production systems and plant protection guidelines in particular have evolved from the contribution of whole sections of farming and biological sciences (Dent 1995). Even so, most plant protection strategies are linked up to the traditional use of conventional and nonselective insecticides. However, the use of pesticides without restrictions is associated with a variety of problems, including environmental degradation, insecticide resistance, negative impacts on natural enemies, and safety for pesticide applicators and the food supply (Cross and Dickler 1994; Altieri and Nicholls 2000; Boller et al. 2004). Concerns about these events have increased the interest in the development of alternative means of pest control that cause little or no impact on humans, beneficial organisms, and sensitive ecosystems (Damos and Savopoulou-Soultani 2011).

Among the available alternative pest control strategies, IPM has by far received the most attention as a comprehensive pest management approach (Lewis et al. 1997). Historically, IPM was introduced using the term integrated control by Barlet (1956) and was further used by Stern et al. (1959), as a concept which in principle is integrating the role of biological and other control measures in complementary ways. Stern et al. (1959)) broadened the conceptual framework of IPM to embrace the coordinated employment of all available biological, cultural, and artificial practices (Van den Bosh and Stern 1969). In this context, various authors have advocated the principle of incorporating all available control methods and measures to manage pests that are being chosen by environmental, economic, and societal standards. Bajwa and Kogan (2002) define IPM as a suitable agricultural approach and as a crop protection/pest management system with implication for both methodological and disciplinary integration in the socioeconomic context of farming systems. Conceptually, the major goal of IPM is not to eradicate all pest populations but rather to accept a tolerable pest density above the economic injury level. The economic injury level is an essential concept for IPM which integrates biology and economics and uses pesticides, or other management actions, only when economic loss in anticipated.

Subsequently, the term IPM incorporates the full array of pest management practices, which are adopted following certain criteria, included into a total systems approach that ideally should involve all crop production objectives. To date, some basic elements, which are considered for IPM, involve (Flint and van den Bosch 1981; Lewis et al. 1997; Duggal and Siddiqi 2008):

1. The use of practical decision tools such as monitoring, forecasting models, and economic injury levels. If available, such tools are traditionally used manually to solve pest problems based on determined need.

2. IPM calls for a multidisciplinary approach. This means that all classes of pests and their relationships, as well as their interaction with other species (e.g,. natural enemies), host, and environments, are jointly considered seeking an optimal and sustainable management policy. Additionally, multidisciplinary management actions are progressively integrated.

3. IPM recognizes the need to address not only ecological but also economic and social concerns.

4. IPM takes into account the human factor as part of the agroecosystem and not detached.

Figures 2 and 3 depict representative integrated peach production orchards in Northern Greece. About 104,000 ha of fruit crops are cultivated and stone fruits represent $76 \%$ of fruit production. In 2007, peach crop production was valued at US \$271 million, making Greece the fifth ranked country in world peach production. Moreover, during the last years, the implementation of integrated fruit production and IPM has not only enhanced the sustainability of fruit production, but also reduced pest management cost and facilitated the acceptance of certified fruits in the markets.

Figure 4 is an example of a biointensive IPM strategy to manage key pest threats. It conceptualizes in particular the creation of integrated pest management and illustrates some of the positive interactions with other pest management 


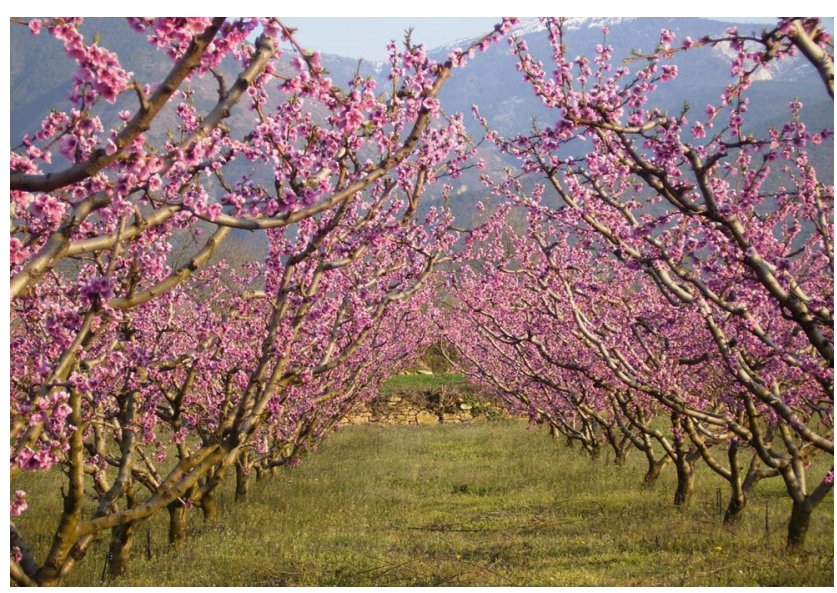

Fig. 2 Typical integrated peach production orchard during the full bloom stage suited in Northern Greece, Prefecture of Kozani-western Macedonia (photo: P. Damos)

activities. The contribution of each activity is represented as a ratio of the triangle. IPM promotes a more diversified approach, which will limit overreliance on any specific technology and promotes greater reliance on exploiting living, selfrenewing processes in pest control, such as the action of natural enemies of pests. Agronomic measures include several techniques and offer a balanced environment for biological mediated soil fertility and sustainable events. Additionally, the use of semiochemical and pheromones in particular evokes the natural pest regulation and further down-energy input. An essential step for the development and implementation of basic IPM program is to have knowledge on detailed and comprehensive data on the life cycles of key pests and how they interacted with their environment. This is a challenging task considering that detailed data upon the key pest and how it interacts with its environment is not always available (Ehler 2006). This knowledge is further combined with the utilization of these control methods that are selected among

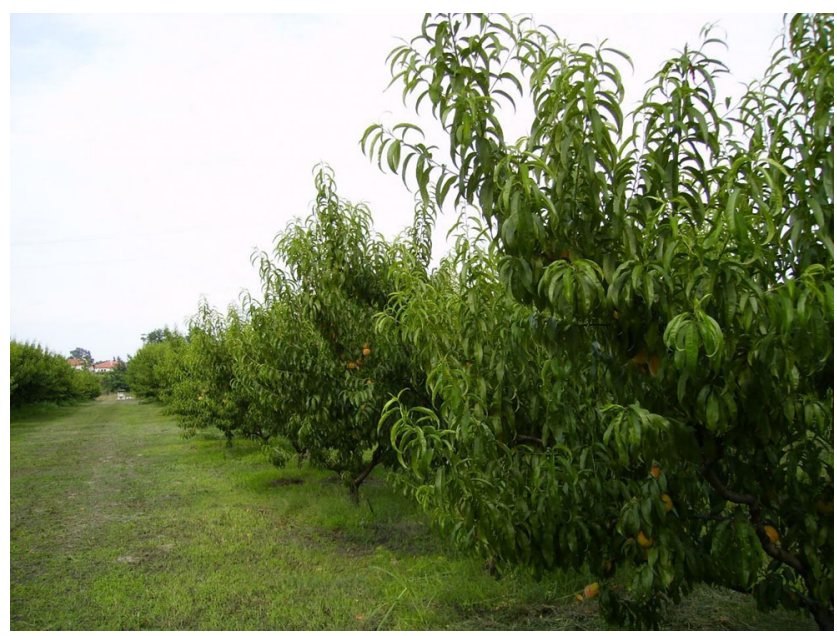

Fig. 3 Typical integrated peach production orchard during the fruit maturity stage in Northern Greece, Prefecture of Imathia-central Macedonia and (photo: P. Damos) several available economic and social factors to have the least possible hazard to people and environmental-friendly means.

However, critical skills in picking out the best management action are early pest information prediction in relation to expert knowledge of the behavior of the pest or pathogen in the specific geographical region of interest. The ability to predict population dynamics and disease development such as population emergence, succession of stages, generations, and early diagnosis is also critical. In this context, having effective models, which can assume the evolution of a disease during the season, is an important matter. These challenges are addressed by decision support systems, which among their aims are to transfer research results immediately to the production floor.

Yet, when it comes to translating IPM in a practice, it is mainly based on pest field monitoring and relative threshold establishment, in which most pesticides are used on a need basis if alternatives are either nonavailable or nonefficient (Flint and van den Bosch 1981; Nutter 2007; Damos et al. 2012). Unfortunately, a good deal of less stress is given to understanding and promoting inherent strengths within systems to limit pest populations through the use of extension and warning systems, and thus, most of this data cannot be directly exploited due to the lack of real-time pest forecasting systems. On the other hand, a rigid application of chemical insecticides on a schedule basis may not always be either necessary or effective, especially if the pest population is low at the time of application. Moreover, in 2009, the EU legislation upon sustainable usage of pesticides has been changed radically, and consequently, the adoption of alternative control methods and the development of decision support systems compatible with IPM are urgent demands. Additionally, the increased legislative pressure on the member states affects plant protection. However, it remains unclear how IPM approaches and crop-specific management actions will be finally adopted, despite that IPM along with organic farming is the only alternative for sustainable agriculture and less pesticide use in the EU (Lefebvre et al. 2015).

Considering the increasing interest of biorational insecticides where precise timing of treatments is extremely important, weather-driven pest and disease forecasting algorithms could be a useful tool for improving their efficacy in IPM and assure fruit-related residual levels at safe intervals. Moreover, the knowledge and technology gaps may affect actual implementation of IPM at the field level. Professionals in the agricultural field, such as growers, extension agents, and researchers, need a facility to predict region-specific pest population emergence and provide decision support for management actions.

Therefore, numerous modeling researches are being carried out, new results are discovered at the research institutions, and they continue to accumulate in the form of reports and run extensions. Yet, most of these findings and recommendations 


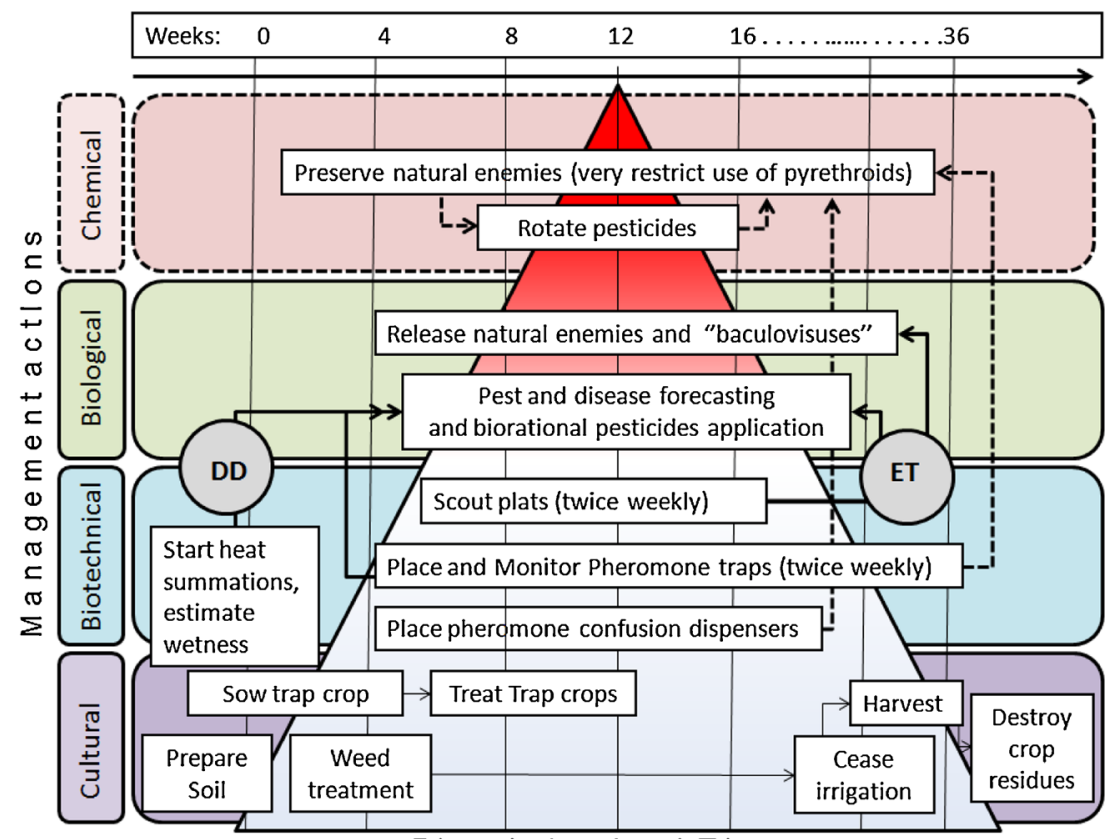

Physiologlcal Time

Fig. 4 Conceptualized foundation of integrated pest management. The triangle represents a biointensive IPM system in which the contribution of each control tactic (cultural, biotechnical, biological, and chemical) is presented with different colors and as a ratio of the expanse of the triangle sector. Note that chemical measures are placed on the top of the triangle and used only under specific criteria (i.e., $D D$ degree-days, $E T$ economic threshold). Critical skills in selecting the best management action are the use of decision tools which provide early pest information prediction (Damos 2013b; after modification)

insect development and succession of stages. The role of pest population modeling for IPM is to aid in determining the optimal control strategy for a given situation (Plant and Mangel 1987), and since pest population models are in the core of almost each decision support system for pest management, we will shortly outline their utility and conceptual framework.

The usefulness of pest and disease models in practical activities such as performing forecasts and identifying warning situations, as well as higher level activities such as gathering biological data, is usually recognized; consider for instance the earlier works of Coulson and Saunders (1987), Logan et al. (1976), Logan and Weber (1989), and Visser et al. (1994). Models have been also established for the description of several pest population processes, including population growth, pest immigration and range expansion, pest emergence and seasonality as well as pest population per se (Cheke and Tratalos 2007). However, only few of these model approaches have been transmuted into practical forecasting tools and related decision support systems. Moreover, because ambient temperature regulates direct development, growth, and reproduction, pest phenology forecasting is established by simplified weather-driven models. However, there are also other factors that may affect population dynamics and insect voltinism, such as photoperiod, humidity, and nutrition as well as crowding, or density and competition (Brown 1984; Rousse et al. 2009). For plant disease epidemics, biotic factors such as wet conditions, relative humidity, wind speed, and 
host suitability are also influential (Teng 1985; Garret et al. 2011).

Nevertheless, here, I focus mostly in insect pests, and in that respect, there are several pest population models that have been developed (Damos and Savopoulou-Soultani 2012). However, most models are based upon the same assumption, which premises that although that development accelerates or slows, according to prevailing temperatures, the final time units to discharge a particular developmental event should be perpetual. Ordinarily, favorable conditions for species' development, insect or fungi, are estimated prior under laboratory conditions, and these estimates are further utilized to simulate epidemiology under field conditions. Therefore, the use of growth chamber studies, carried out under controlled conditions, is a prerequisite since they provide a satisfying base for understanding the effects of environmental factors on species ontogeny and vital to estimate the species temperature thresholds (Logan et al. 1976; Beck 1983; Damos and Savopoulou-Soultani 2008, Ferguson et al. 2015).

Figure 5a shows the typical temperature effects on developmental time and Fig. $5 \mathrm{~b}$ the two developmental rate models, which can be linear or nonlinear. Such kinds of inverse regression, displayed in the above paradigm, are used most often to define the vital for species development temperature thresholds. The values of the lower, the optimum, and higher temperature thresholds are a prerequisite for accurate modeling and projection of pest dynamics. Yet it is noteworthy to say that the most time-consuming step in the evolution of a model is the aggregation of biological knowledge of species of interest and relevant weather input parameters. In that respect, it is noteworthy to cite Nietschke et al. (2009) who created an insect development database, which includes developmental requirements for over 500 species to assist scientists and field practitioners in the deployment of phenology models.

The next step requires the application of population models and species temperature thresholds to simulate actual pest population dynamics under field conditions. There are various methods and models (i.e., see Sharpe et al. 1977; Pruess 1983; Wagner et al. 1984a; Kontodimas et al. 2004; Van der Have 2008; Damos and Savopoulou-Soultani 2012), but for the reason of brevity, we will mention only the two most common approaches applied in entomology: the physiological time concept and empirical regressions between accumulated degree-days and cumulative population emergence.

Physiological time is using developmental rate models, which assume that rates are proportional to temperature, and as amounts are integrals of rates, the amount of development is the inbuilt of the temperature. The rate of development is simulated as linear or nonlinear function of temperature along a time axis and has units of temperature and time, which are known as degree-days (Pajunen 1983). Significant models for modeling the effects of variable temperatures on the
Developmental time

(days)

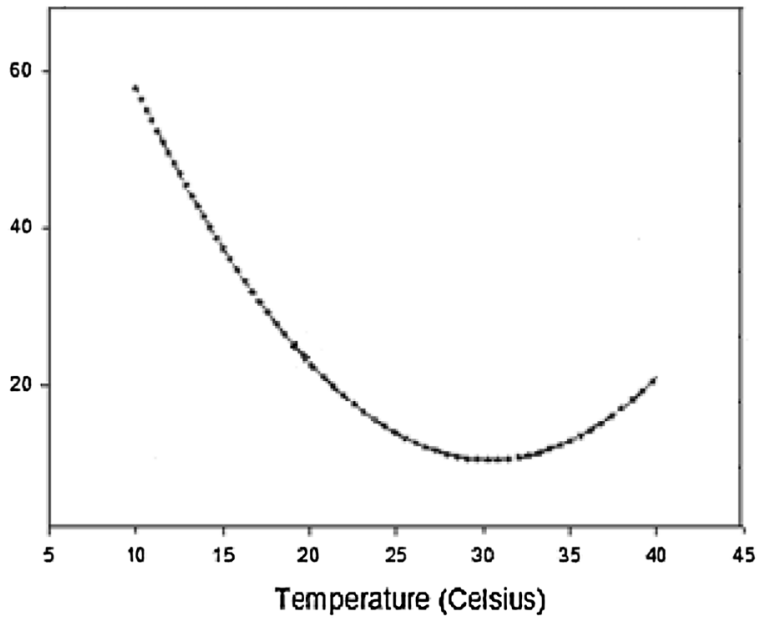

Developmental rate

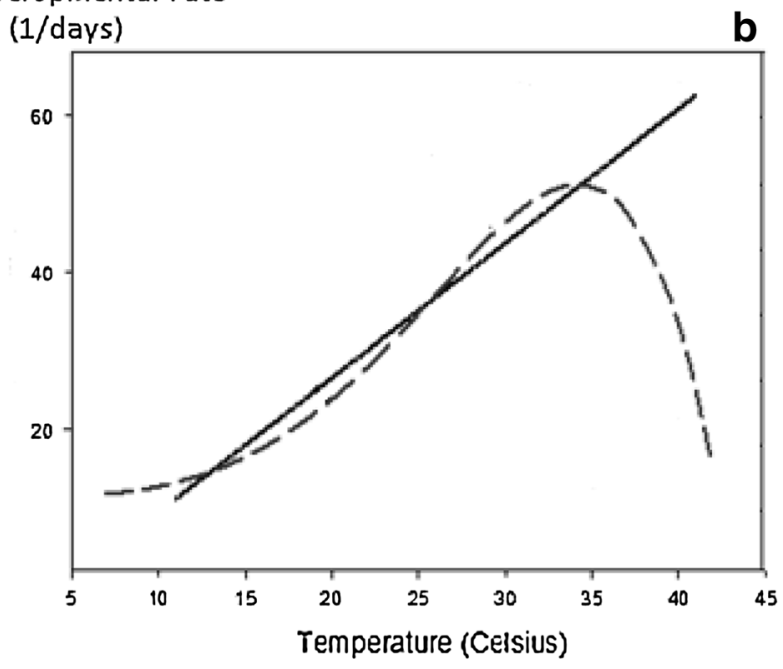

Fig. 5 Typical responses and temperature effects on pests' developmental time (i.e., arthropod pest) under laboratory conditions and related linear and nonlinear developmental rate models. Extrapolations of these models provide estimates of the lower and upper developmental thresholds

development of individual insects, within a given population, may also deal with mean rate versus temperature relationships (Wagner et al. 1984a) and distribution of development times (Wagner et al. 1984b, 1985).

Empirical approaches, on the other hand, treat mean developmental times as dependent variables, which are regressed over accumulated degree-days that serve as the independent variable. Such models are usually based on nonlinear regression relationships. In their simplest form, for example, adult emergence is regressed over accumulated degree-days above a threshold. Hither, the moth capture data consist of the random variable and temperature represents a deterministic quantity. The Richards' function, or the generalized logistic curve, is sshaped mathematical functions, which can be turned around to 
be consistent with the most conceivable variations of their basic form. The shape of the curve described in Fig. 6, for example, is a mutation on the original published curve of Damos and Savopoulou-Soultani (2010) and can draw most datasets with high accuracy. Empirical models are most useful in predicting adult moth emergence and population peak and are widespread due to simplicity for construction and evaluation, while validation of models is using a variety of laboratory and field experiments.

Fungal diseases, on the other hand, develop not simply in close correlation to temperature but take also into account more meteorological parameters, particularly relative humidity and moist condition (Perini and Susi 2004). The downy mildew (Plasmopara viticola) for instance needs specific temperatures and leaf wetness conditions for sporulation. Subsequently, the epidemic dynamics over time can be described using growth models or disease progress curves (Agrios 2005). By applying similar mathematical tools, as in the instance of insect phenology models, disease models are trained to get data about the theoretical appearance and the quantity of inoculum changes during the growth season. To date, the most common monocyclic and polycyclic growth descriptions growth include: monomolecular, exponential, logistic, and Gompertz models (Nutter and Parker 1997; Xu 2006). In temperate climates, environmental conditions are registered at distinct time windows during the growth season and used to run the models. By this manner, it becomes possible to predict with quite a high precision the proper time when infections may do appear (Fig. 6). More complex simulation models may additional include the life cycle of the host crop, the feast of

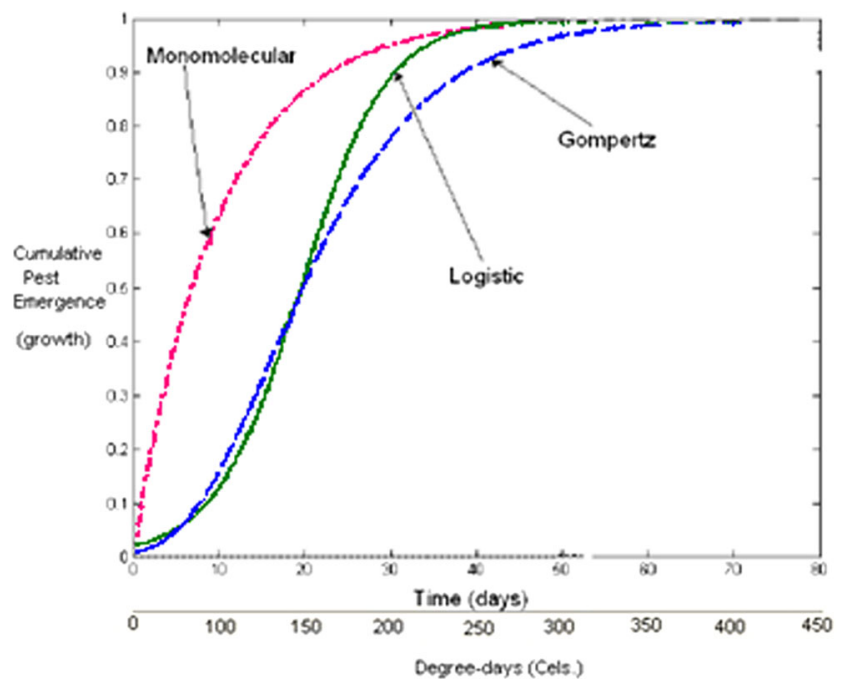

Fig. 6 The shape of representative temperature-driven phenology models which are regularly used to predict pest phenology (insect emergence or disease growth). In the case of arthropods, pest phenology models help to predict the timing of events in an organism's development using degree-days. Degree-days permit to predict significant biological events such as the appearance of insect pests that may occur during the growth season the pest agents to distance crops as well as the influence of several other biotic and abiotic factors (Andrade-Piedra et al. 2005; Kaundal et al. 2006; Cairns et al. 2008; Khaliq et al. 2014). Thus, pest forecasting is a fundamental step in creating proper IPM programs (Van Maanen and Xu 2003).

Functionally, because temperature exerts the greatest influence among the climate variables, by directly affecting insect phenology, most pest models are temperature driven. On the other hand, plant disease models take into account more variables such as wet conditions and relative humidity. Fungal growth is strongly affected by environmental conditions, and therefore in most cases, there is a time lag between infection and appearance of visible symptoms (Magarey et al. 1991, 2007). For example, fungi spores germinate and cause infection only when they are kept at a certain period at favorable temperatures and at same time must be continuously wet for certain hours. Hence, plant disease forecasting models provide output risk levels, which are helping the growers to assess the risk of disease epidemics and to avoid unnecessary treatments with fungicides (Pavan et al. 2010).

Concluding, accurate forecasting of pests is facilitated with the use of climatic-driven models. These models offer a mathematical framework that helps to predict the development of pest's stages, or latent phases of diseases to define optimal time windows to apply pesticides. Nevertheless, the next step for a wider applicability and application of models under a routine field condition basis is to use pest population models across locations and real environments in an automatic manner (Coulson and Saunders 1987). To address this challenge, it is necessary to develop computer software programs, as described below, to run the models and facilitate the practical application by understanding population dynamics and dissemination of pest forecasts for timely pest management decisions.

\section{Data processing and forecasting algorithms: modus operandi of computer-aided decision support}

To exploit large datasets to be used as inputs for a certain population model implies the development of algorithms, which serve as a basis to develop computer programs to simulate pest phenology. This section describes in the conceptual framework that can be generally followed for the development of forecasting algorithms. The approach should be considered as typical, although the given examples are those followed by Damos and Karabatakis (2013). Actually, there are very few published works that provide a robust framework and opensource programs or algorithms that can be used ad hoc in decision support systems (Higley et al. 1986; Bery 1995; Don Wauchope et al. 2003).

Algorithms are computer programs that handle the data and transform them into relevant and understandable information 
(Croft et al. 1980; Coulson and Saunders 1987). Database management system software (DMSS) is traditionally used for such purposes. The core of the software is a "prediction algorithm," which is a sequence of logical operations under certain predefined rules. The algorithm then picks out the suitable data entry among available information and stores them in a local host. In a second step, the algorithm uses these data as input for the pest model to simulate population projections and service warnings.

Thus, prediction algorithms refer to simple software that allows a candidate phenology model to pick up those factors most closely related to prediction and perform related forecast. From a programmer's standpoint, this implies the development of a set of rules that precisely define a sequence of operations in a specific order (Khaliq et al. 2014). The technological aspect of developing an algorithm involves usually splitting the task into subtasks. These subtasks are at best modular and perform subroutines having clearly defined boundaries (Youen et al. 1996; Damos and Karabatakis 2013; Karabatakis and Damos 2013).

Figures 7 and 8 present the principal logical operations and subroutines that are involved to perform a forecast for an insect pest and plant disease, respectively. Figure 7 shows the basic logical operations (flow diagram) of an insect phenology model. The process model starts from overwintering larval diapause termination and moth emergence until the emergence of the first summer generation larvae and considers the different insect stages of the first generation. Heat summations, SUM $\{\mathrm{DD}\}$, are expressed as accumulated degree-days according to a predefined heat summation function, $F(x)=Y$. This function corresponds to a developmental rate model, physiological or empirical, and is used to generate stagespecific forecasts. Figure 8 depicts the basic logical operations of an Oomycota fungal disease phenology model (Magarey
Fig. 7 Basic logical operations (flow diagram) of the phenology model simulating progress of an insect pest population (i.e., Class: Insecta). LTT lower developmental threshold, HTT higher developmental threshold, SUM $\{\mathrm{DD}\}$ : accumulated degree-days according to a predefined heat summation function, $F(x)=Y$ : developmental rate model; $a, b$, and $c$ : threshold values that predefine the emergence of the first generation of adults, larvae, and eggs, respectively

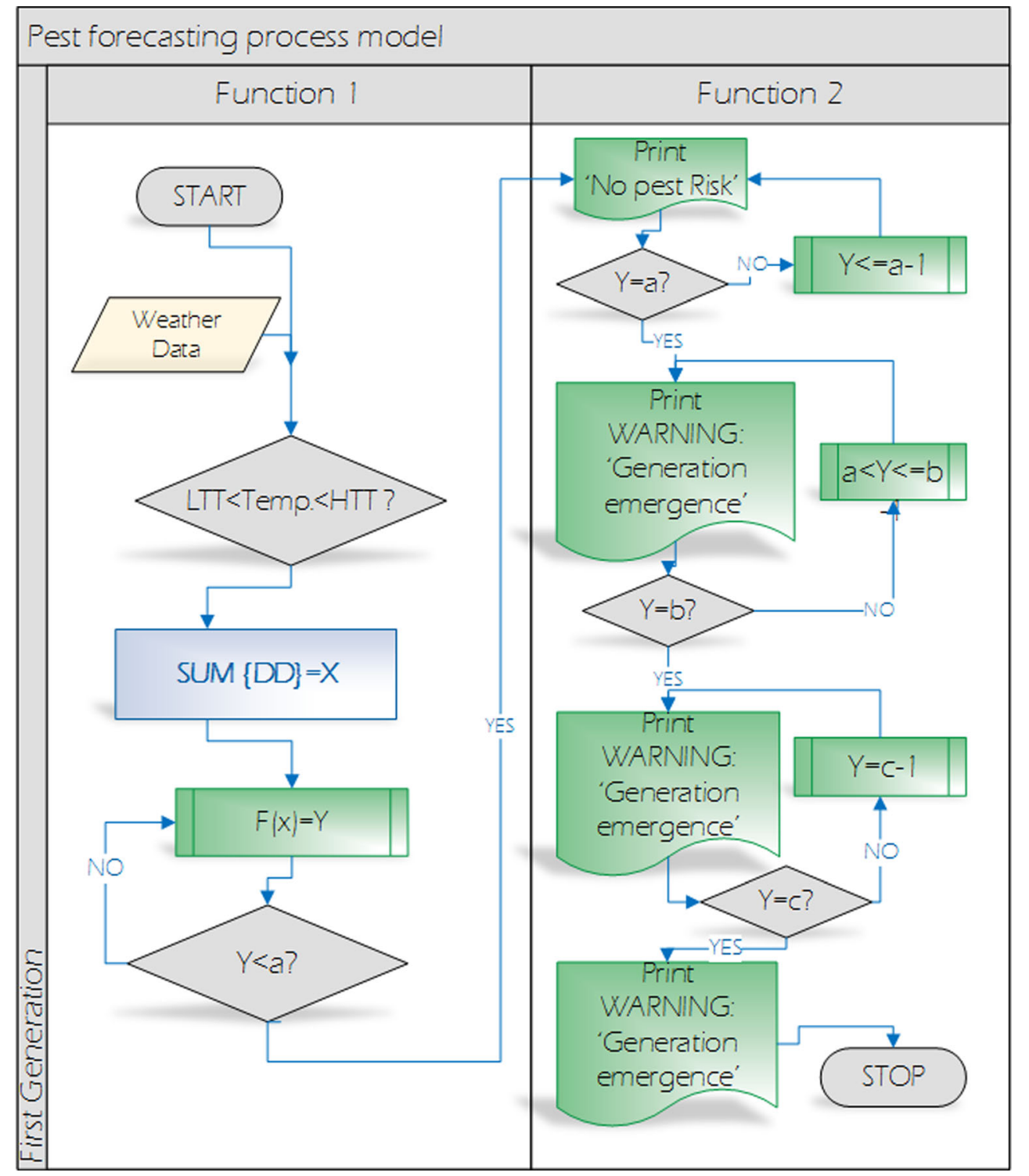




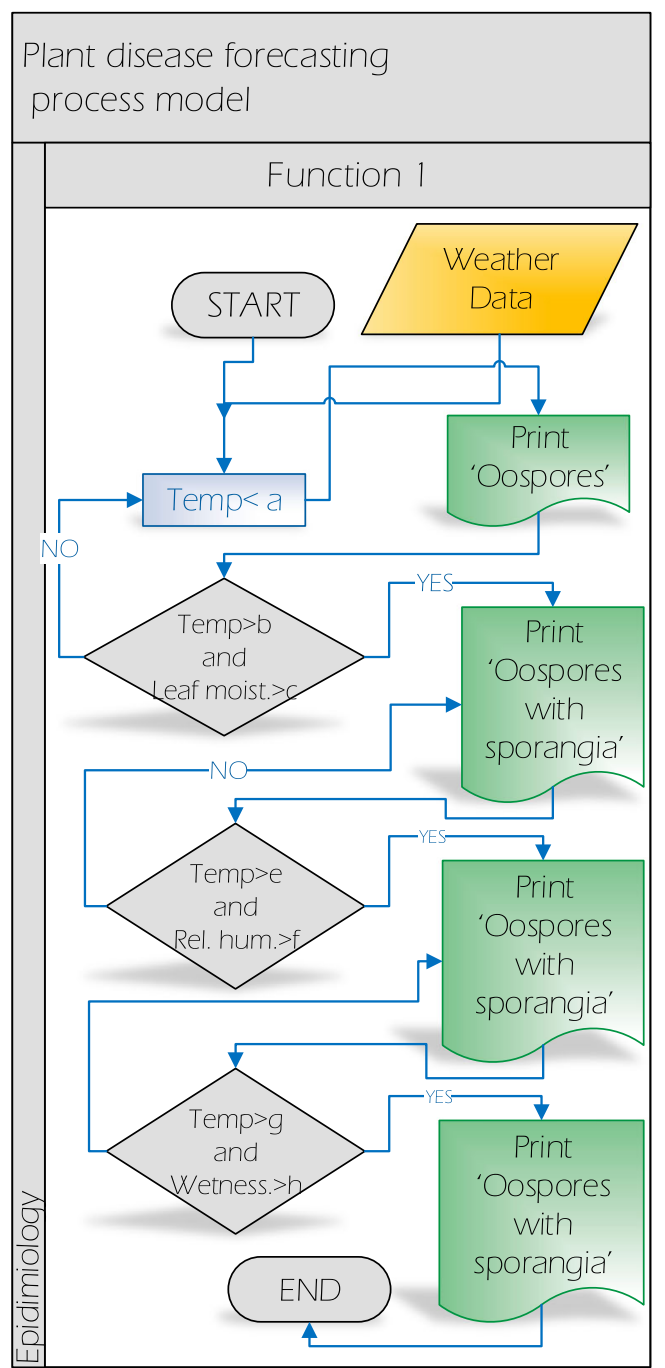

Fig. 8 Basic logical operations (flow diagram) of phenology model simulating development of fungal disease (i.e., Class: Oomycota) and related infection risk warnings

et al. 1991; after modification). The process model starts from oospores until the appearance of symptoms. Note that the process considers the distinctive stages of the primary infection cycle. Overwintering oospores progressively break diapause and germinate under favorable weather conditions (temperature and humidity), while the formed sporangia release zoospores. If the conditions remain favorable, the zoospores form germ tubes and infecting hyphae colonize the host tissue and cause observable symptoms.

Typically, when the algorithm is associated with data processing information, the values are interpreted from an input source, written to an output device, and/or stored for further processing. Next, subroutines are performed which include the setup of "weather rules" as for example the definition of temperature thresholds which serve as bounder to draw and store data. In a second step, the detailed specific instructions are used to transform these weather data into an exploitable model format. Most insect pest models transform the mean temperatures to accumulated degree-days and then use them to feed an empirical population model. Finally, specified tasks are carried out such as population projections and initiation of warnings. For the needs of computer programming, the two forecasting algorithms were created as functions, which served as small programs, referenced by the larger final program of the decision support system. Among the weather variables, which affect mostly population phenology and disease epidemiology, are temperature, relative humidity, rainfall, and wet conditions. Based on the regional climate data, a prediction algorithm can forecast the pest's population occurring during the growth season.

Concluding, improvements in hardware technology have permitted the registration of automatically recorded data and other pieces of data, which can be employed in pest modeling. Improving simulation models that integrate the dynamic effects of climate variables on pest population can be automated through the development of algorithms that serve as small computer programs. Usually, the algorithm is represented with a form of diagrams, referred to as flowchart, and then each logical operation is put up using one kind of programming language. Furthermore, the algorithm is providing a visual representation of theoretical constructs, including interactions of the variables of interest and actually consist of a conceptual model (Asher 1984). In its crude form, it is represented as a flowchart diagram which treats the pest population as the dependent variable and the weather variables as independent. The arrows represent the hypothesized relationships between variables leading from each determining variable to each variable conditional on it. Critical values of parameters that affect pest populations are established as rulers. If suitable conditions for pest emergence or disease development occur, then the algorithm provides outputs, which can guide decision making in IPM. To date, in contrast to manual modeling, the use of algorithms is a more advanced, more accurate, and realistic way of pest forecasting. In addition, once the routines have been established, the model works on its own and can be extended according to the needs by including more datasets and rules. Hence, although simple predictive models for pests and diseases have been produced during the last century, the development and wider availability of personal computers resulted in the speedy growth of computer-based examples to predict responses of pest populations in relation to climate.

\section{Interface of web-based decision support systems}

Successfully supporting IPM decision making is critically dependent upon the availability of integrated, high-quality information, organized and delivered in a timely and well-read 
manner (Bajwa and Kogan 2000; Duggal and Siddiqi 2008; Philomine et al. 2012). In the next paragraphs, I will describe some instances on how forecasting algorithms can be merged with information science toward the development of simple forecasting systems.

The first step requires the use of DMSS, which incorporates the prediction algorithms and may be enlarged to a DSS. This may include more variables and/or new improved population models, which preferably perform operation through the www and permit the improvement of existing algorithms in future software updates. Moreover, DMSS may be utilized to create tables of data, to construct user interface, to design queries, and to print out the required summary reports (Batchelor et al. 1989; Jones 1989; Zhang et al. 2008; Kleinhenz and Rossberg 2008; Plénet et al. 2009).

Recently, semantic network interfaces such as Drupal (https://www.drupal.org/) permit logical dynamic web programming. The most common web programming language is python, PHP 5.2, or higher and may serve as online interface to configure the decision support system of interest. This enables the use of climatic data processing and prediction algorithms to transfer data to a central server in a real-time manner and matching the frequency of updates to the initial pest forecasting system design requirements (Strand 2000). At a second stage of the data processing, a forecasting algorithm application handless the data and aggregates the raw data into relevant and understandable information. In addition, grounded on the end product, which is awaited from the decision system, input data are marked by specific attributes. These attributes may include for instance hourly and/or daily data registration and may be manipulated and programmed, under diverse manners to meet specific objectives. In most cases, the aim is to perform pest population simulations and projections to provide the user with real-time warning and/or recommendation-specific management actions.

In Damos and Karabatakis (2013), for instance, a webbased decision support system has been developed for climatic factors including region-specific average temperature, to predict pest population phenology during the growth season. The DSS particularly offers forecasts and related management actions with peach and apple orchards, including warnings for Anarsia lineatella Zeller damaging peach, the leaf roller Adoxopyes orana Röslerstamm, and the oriental fruit moth Grapholita molesta Busk. At a first step, the stored temperature data are evaluated on a daily basis whether they are in between the species-specific temperature thresholds, and if so, they are transformed to degree-days. This transformation is performed according to a predefined nonlinear or logistic regression function (Damos and Savopoulou-Soultani 2010, 2011). In a second step, the degree-day data are summated and used as input for the phenology model that is used to provide warnings of whether the species is higher than a predefined population level. The pilot project is the IPM-
DSS RANTISMA.gr that is able to perform population projection either numerical and/or discretional by plotting the cumulative emergence of the species for the particular region of interest (Fig. 9). The software and the related web application were launched on January 2012 (Damos and Karabatakis 2013). Functionality of the software can potentially extend and mine weather data at any location through the www and further store them for any use (i.e., crop, pest, and disease modeling and forecasting). Currently, the above DSS passes the evaluation phase and runs only for representative arthropod pests, since the development of disease models may be considered more complicated because they use climatic models which take into account both temperature and wetness. The wetness, or the wetting period, refers to the time that a plant organ is exposed to liquid water constituting an important factor in the disease development.

Despite efforts that have been made previously to provide local forecasts, based on weather data, in most cases, the legal transfer of automatic forecast system having wider applicability stubs on the high costs of procurement, complexity, and maintenance and/or on noncontinuous "feed" of the system with weather information. However, grounded along the above framework, IPM can be significantly amended by the utilization of modern emergent information web technologies. Such simple handling web-based DSS can be exploited by extension agents, advisors, growers, and other clientele, providing forecast along with efficient decision support for managing agricultural commodities. Actually, real-time forecasting and decision-making systems provide rationale mean to assist crop growers at the farm level in finding out whether pesticides or other measures should be utilized.

\section{Ontology web programming: the next generation of web-based decision support?}

Ontology is an explicit specification of conceptualization for describing a particular knowledge domain using logical relations. In computer science, ontology web programing is a formal way to classify and describe data taxonomies to facilitate knowledge information sharing over distributed systems (Athanasiadis et al. 2009; Taye 2010 and references). Here, I intend to provide a brief account on emergent web technology for interlinking and classifying agrodata to be exploited by DSS and in the IPM domain.

Ontology plays a major part in solving the problem of interoperability between applications across different organizations as for instance the exploitation of a huge quantity of agroecological data, which are typically unclassified and stored individually and/or fragmented on local server files. Thus, the use of ontology web programing provides a shared understanding and access on data for future manipulation and 


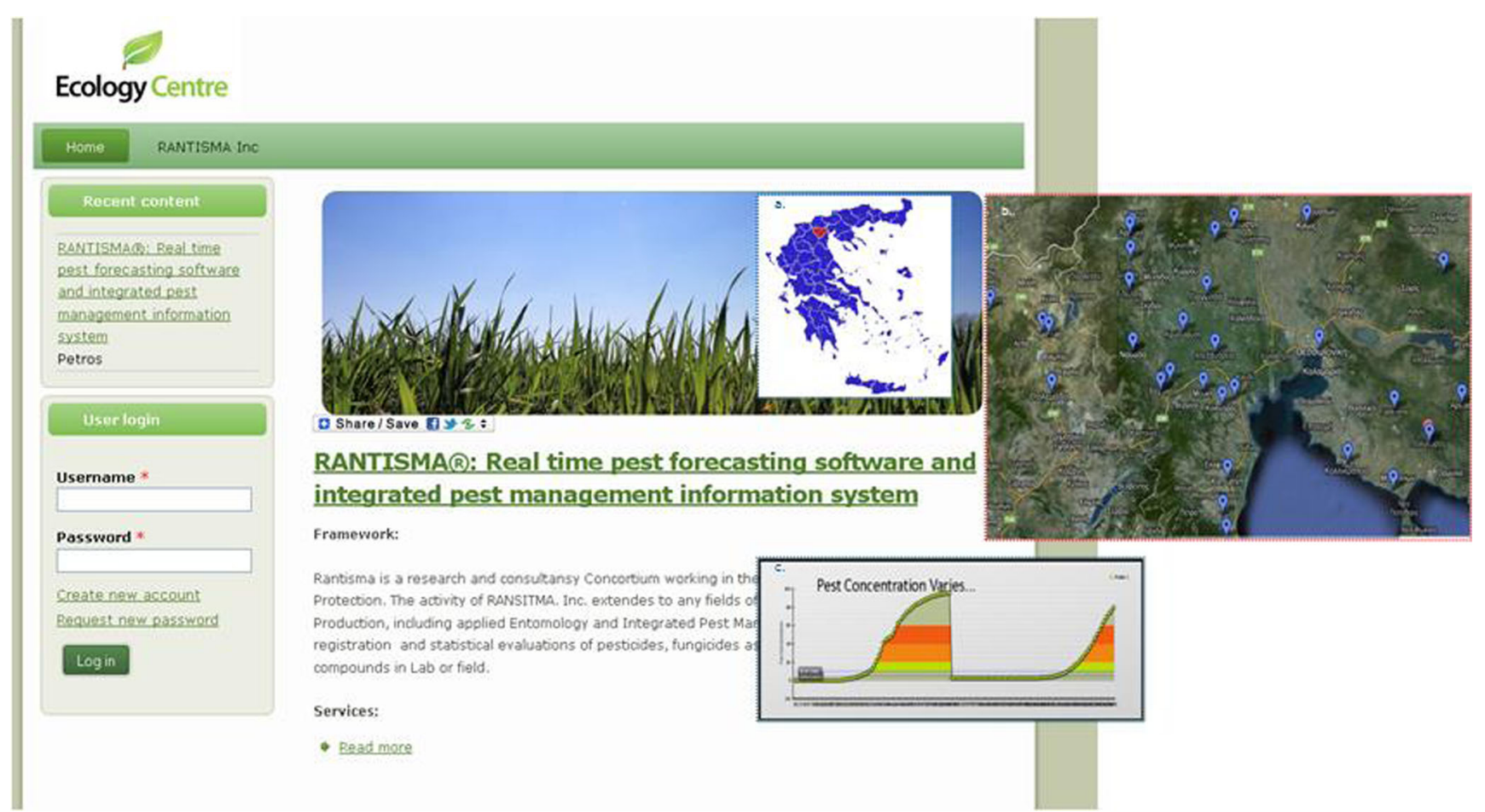

Fig. 9 Web interface of the pilot web-based real-time integrated pest management decision support systems RANTISMA and related forecasts of pest emergence (first and second generations - cumulative) in Northern Greece. Samples in the map indicate locations where forecast is running

meta-analysis (Van Evert and Campbell 1994; Bajwa and Kogan 2000).

Professionals in the agricultural field, such as growers, extension agents, and researchers, need a facility to organize and locate pest-related information. For example, photographic images, pesticide categories, and registrations are related to their oeuvre, especially as the bulk of information continues to increase. Nevertheless, current keyword-based information retrieval in DSS and related information systems suffers from relatively low precision and recall. Currently, the information, which is received from web applications, is without any sensible mean of representation in contrast to semantic, or ontology-based, web applications which provide annotated data that can be understood by machines. Thus, novel approaches to information retrieval using ontologies in the agricultural field may address the limitation of supporting users to find proper information in keyword-based retrieval, by browsing information associated with formal descriptions of the significations of words. This is referred as semantics and the relationships between different objects are made using ontology web language (OWL) (Haverkort and Top 2010; Caracciolo et al. 2012).

Currently, detailed usage of ontology web language is used by applications that need to process conceptually the content of information instead of just presenting information. The language facilitates greater machine interpretability through web browsers and supports the use of different data sources and web programing schema, such as extensive markup language
(XML) and the resource description framework (RDF). The resource description framework is a general method for conceptual description of information and is based on class diagrams in the form of subject-predicate and object expressions. In addition, it permits converting relational databases (RDBs) to RDF data.

To date, other software systems offer access to the content of relational databases and interlinking data through link discovery frameworks for the web data. Such systems are the program SILK and the RDF query language SPARQL SERVICE.

The above technological tools combined with other services can be used to offer a unified taxonomy that relates different entities and attributes, in conditions of the ontology as set by the World Wide Web Consortium (W3C) (Damos et al. 2012; Damos 2013b).

Actually, the resource description framework introduces the notion of a class. Formally, the class is a type of thing. For instance, Farmer_1 and Farmer_2 are members of the class Cooperatives. Thus, we define Farmers as a member of the class type cooperatives. We can further proceed to define subclasses, attributes, instances, and so on. For instance, the classes insecticide, fungicide, and herbicide are subclasses of the class Pesticides. The next step is to construct ontologies for some cardinal datasets to facilitate information retrieval. This is feasible after prior examination of data types and major data properties and to classify those of similar topics. 
Stanford University has developed a free open-source software ontology editor under the name Protégé. The editor offers a knowledge-based framework to relate semantic entities and for building intelligent systems on an easy handling environment (http://protege.stanford.edu/). Hence, ontology is composed of five basic modeling primitives, containing concepts, relationships, instances, axioms, and functions, while agricultural ontology is specified as a set of formal, explicit specification of a shared conceptualization in agricultural science (McRoberts et al. 2011; Cowell and Smith 2010; Caracciolo et al. 2012). Therefore, it is convenient to categorize first agronomy data according to their attributes and fix categories of information. In principle, each agricultural (pest and disease related) data source can be sent to and/or retrieved on the network due to a singular universal resource identifier (URI) (Damos 2013b). The construction of a related pest ontology can be applied to place and link digital objects which may be further utilized for decision support. Information may include for instance pesticides and chemical ingredients authorized for application, prices of pesticides in relation to company, chemical ingredient and biodegradability, application mode and pest targeting stage, pesticide per harvest period, information concerning life cycle and type of damage, pest morphological characteristics and disease symptoms, etc. (Coulson et al. 1989; Haverkort and Top 2010; Damos 2013b). At a second stage, graph-based ranking algorithms can be successfully employed in data summarization, while several query expansion methods (Chakrabarti et al. 1999) can resolve information limit on the query based on the prior defined ontologies. These methods are largely inspired by the PageRank algorithm, or manifoldranking algorithm, which is initially applied to the task of web search and has been proven successful (Page et al. 1998).

Figure 10 shows the parts of a hybrid web-based pest forecasting and information system for IPM, which is using both DMSS and related prediction algorithms (left position), as good as the basic pest ontology (right position). Ideally, such ontology is useful in linking huge datasets posted on the web and may serve as an information and decision tool for the plant protection agencies to ease searching and browsing of pest management-related information (Koenderink et al. 2005). The ontology can describe the properties, or attributes, of careful scientific defined concepts. For example, the attributes may include specific properties of chemicals that are used in IPM such as their properties including chemical class, type of water formulations and environmental behavior, application doses and lethal concentrations, mode of action, lethal concentrations, application type, monetary values, preharvest type, and registration. Additionally, the ontology addresses instances such as application type and time, pest target, spectrum, and side effects. Specific zoological vocabulary can be employed to describe structural and biological attributes of the selected pests. This kind of taxonomy may include information on taxa, scientific and common names, colors, stages, life cycle, number of generations, habits, reproductive potential, vulnerable stage, and other data. However, most available ontologies provide either domain vocabulary for semantic interoperability of systems or deal with limited situations and are not scalable. Moreover, few scalable and distributed ontologies are available for the agriculture domain, but they are component oriented, such as ePlant and eGadget, and generate complexities in case of multiple service requirement at a time (The Plant Ontology Consortium 2002; Goumopoulos and Kameas 2009; Rehman and Shaikh 2011).

Evidently, at a high-level system view, the primary advantage of using ontologies in DSS is that it permits synthesis toward hybrid DSS in decision making, for example, communicating predictions and artifacts of ontologies in the form of classified information, in which two or more aspects of the same problem are taken into a balanced consideration at the same time. Thus, as part of pest and disease forecasting, IPM shows that there is vastly too much data for a human to comprehend at one time, and therefore, ontology-based DSS may provide services to the direction of decision making rather than to simple decision support. This may be feasible because conceptually ontology web applications are based on artificial intelligence and provide information that can be interpreted by computers providing solutions to certain combinations, instead of just serving pages that are meant to be read by humans.

In summary, ontology web programing allows interoperability, exchange, and sharing of pest-related data among corporations and certification authorities and may permit the development of smart web applications with lower reliance on operator assessment. Additionally, it provides a unified way for agrodata management and collaboration among expertise and facilitates the implantation and evaluation of IPM systems over large scales (i.e., prefecture, country, international level).

\section{Instances of web-based decision support for integrated pest management}

Although simple predictive models have been produced during the last century, the development and broader accessibility of personal computers in the 1970s and 1980s (Coulson and Saunders 1987; Higley et al. 1986) resulted in the rapid growth of computer-based models to predict responses of insects in relation to climate (Batchelor et al. 1989; Beck et al. 1989; Bange et al. 2004; Liao 2005; Hannon and Ruth 2009; Orellana et al. 2011). Currently, several IPM-related databases and model applications are placed on the web and can potentially be utilized for information/data collection, distribution, or data exchange (Bajwa and Kogan 2000; Huang et al. 2008, Yelapure and Kulkarni 2012). In this section, we will refer to some of their representatives. 


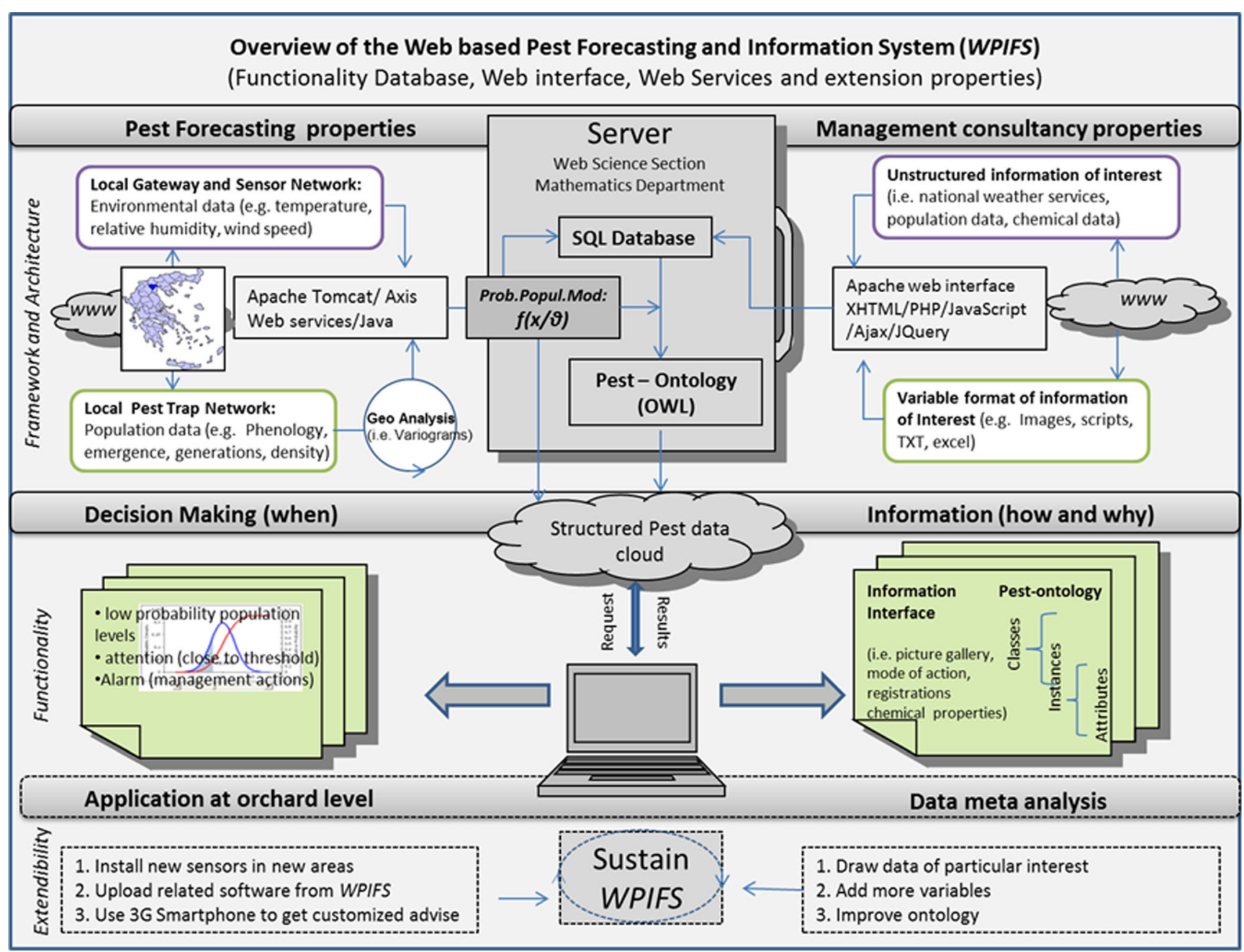

Fig. 10 Properties (architecture, functionality, and expendability) of a hybrid web-based forecasting information system which is based on both: real-time forecasting service and query expansion properties using related pest ontologies and semantic computing. [SQL Structured Query Language, designed for managing data held in a rational database management system, $O W L$ ontology web language, $R D F$ resource description framework, $X M L$ extensible markup language, Apache HTTP Server: is the most popular world wide web open software server

The preliminary analysis of the literature showed that most IPM support systems and information are static, which means that they are available on the www but in the form of static web pages. Therefore, the information they contain is delivered to the user exactly as stored, in contrast to dynamic web pages, which are user interactive and provide a service through a web application program. For instance, most include electronic versions of informational brochures, pesticide recommendations, fact sheets, reference guides, and bibliographic references, while some of them use web databases that include records of pest phenology, occurrence and distribution, pest control recommendations, or pesticide information. These are mostly used for information purposes and the lack of any ontology and data classification, which may allow a semantic inference. Hence, web sites with working with wide variety of operating systems (i.e., Microsoft Windows, Unix, Linux, etc.), PHP: hypertext processor (server-side scripting language) for web development, JavaScript: client-side scripts for web development; Ajax: web applications techniques that can send data to, and retrieve data from, a server asynchronously (in the background) without interfering with the display and behavior of the existing page; jQuery: a fast, small, and feature-rich JavaScript library with an easy-to-use application that works across a multitude of browsers]

information sheets cannot be classified as a decision support system. Bajwa et al. (2003) provide a forum of a sample array of data resources for IPM research, extension, teaching, and learning, accessible because of the Internet.

Nevertheless, few dynamic and interactive decision support systems have been also developed for forecasting insect and disease outbreaks, while customized web-based applications are likewise rising. An instance is the Pacific Northwest IPM Weather Data and Degree-Days Website (http://www. orst.edu/Dept/IPPC/wea/) and the Swiss Federal Administration Forecasting tool SOPRA (http://www.sopraacw.admin.ch/e/info.php?Lang=e) (Samietz et al. 2008). Such systems move beyond simple information retrieval and IPM query expansion and support the users in the decision management process. The SOPRA DSS uses time-varying 
distributed delay phenological models and provides forecasts for eight major insect pests of fruit orchards on regional scales over Switzerland and Southern Germany (Samietz et al. 2008). Moreover, the system is able to compute the risk degree related to scab disease infection, given the meteorological values and the presence of ascospore ready to pass from the first stage, the ascospore maturity, to the second and most dangerous stage, which is the germination and penetration.

For complementary reasons, I will discuss next few more pest DSS and which I consider every bit more representative, while several other dynamics pest management DSS that are available online are summarized in Table 1. For a thorough literature review of different expert system methodologies and applications in different fields of science, the reader should refer to Liao (2005) and references given.

One of the earliest particular examples, for instance, includes the support scheme for forecasting the black bean aphid (Aphis fabae) outbreaks in fields of spring-sown beans (Knight and Cammel 1994). The system which provided information to the user on individual characteristics of the field and crop, which are known to affect aphid colonization, such as field shape, size, plant density, and the sowing date, was used to adjust the area forecast for the specific field. The system provided also a module for estimating the costbenefit of applying registered pesticides.

In the Netherlands, Dutch farmers have been also using DSS from the late 1980s and early 1990s as an aid in the control of pests. This started with EPIPRE and then weatherrelated potato blight warning systems were developed such as Prophy and Plant-Plus and GEWIS which predicted the effectiveness of application times. The use of these systems resulted in more sustainable crop protection (Bouma 2004).

Another example is the decision support system developed by the Australian cotton industry (CSIRO: Commonwealth Scientific and Industrial Research Organization) in collaboration with University of Western Sydney to reduce pesticide risk associated with pest management (Hearn and Bange 2002). Such systems take into account the regional forecast and additional information provided by the user to individual characteristics of the field characteristics and contain modules of insecticides that are made for use on spring beans and calculate the economics of application (Knight and Cammel 1994).

Elliott et al. (2004)) have developed a web-based decision system for the green bug (Schizaphis graminum) management that is utilizing four modules: aphid identification, the economic threshold calculator, insecticide selection, and natural enemy identification. More recently, Backoulou et al. (2014) have developed a web-based decision support system for managing the economic importance panicle caterpillars in Sorghum. The related decision support system calculates the economic thresholds for this pest, and the related expert system is based on a knowledge representation model.
Enviro-weather decision support system This is a collaborative project between the Michigan Climatological Resource Program and the Michigan State University Integrated Pest Management Program. The software goes through a world wide web interface for weather-based instruments and serves as sustainable weather-based information system that helps users to make pest, plant production, and natural resource management decisions in Michigan (available at http://pest. ceris.purdue.edu/pests.php).

MyPest page-IPM pest and plant disease models and forecasting This website brings together US weather data and plant pest and disease models to serve many decision support needs in agriculture. Presently, this website offers over 80-degree-day and 21-h weather-driven models serving many IPM, regulatory, plant biosecurity, biological control, and conservation uses for the entire USA, with emphasis on IPM needs of the western States (available at http://uspest.org/ wea/).

The UC-IPM online, state-wide integrated pest management program The UC-IPM offers interactive tools and examples that can help farmers make pest management decisions based on site conditions. The site additionally provides information about managing pests, including the University of California's official guidelines for monitoring pests and using pesticides and nonpesticide alternatives for managing insect, mite, nematode, weed, and disease pests as well as other related data. One disadvantage is that the scheme cannot provide individual results to specific pest problems. One additional requirement is that the user must upload specific files and sample data (available at http://www.ipm.ucdavis.edu/PMG/ crops-agriculture.html).

Norwegian agricultural network: pest forecasting The system uses a network of 52 automated weather stations in Norway and is operated by the Norwegian Crop Research Institute. The primary destination of the network is to contract the role of pesticides, resulting in better crops, at lower costs, and in a more honest environment (available at http://www. campbellsci.com/norwegian-network). Data from the stations are used in forecasting models that seek to offer early warning of conditions such as apple scab, potato late blight, cabbage moth, cereal diseases, and turnip moth.

RANTISMA The real-time pest forecasting software and IPM information system are a simple handling software, which runs $24 \mathrm{~h}$ through the web and is available as $4 \mathrm{G}$ smart phone application (Damos and Karabatakis 2013). The system conducts weather data web mining and storage and performs real-time pest forecasting for fruit orchards in distinct geographical regions distributed all over Greece. The registered user has the option to be directly informed through e-mail and/ 
Table 1 Representative pest management decision support systems and related pest population modeling applications available throughout the www

Acronym Main task, objectives, and services $\quad$ Institution/location Reference

CALEX CALEX is a user-friendly computer program that simulates human problem solving behavior. Growers can use this system to help manage crop production or predicts the effects of any one decision on subsequent events. CALEX contained plant and pest simulation model for the purpose of pest diagnosis

CARMA The Case-based Range Management Advisor (CARMA) is a decision-support system for grasshopper infestation which employs a variety of artificial intelligence $(\mathrm{AI})$ techniques to provide advice about the most environmentally and economically effective responses to grasshopper infestations.

CIPRA Computer Centre for Agricultural Pest Forecasting (CIPRA) contains real-time weather-driven bioclimatic models for a total of 35 pests ( 25 insects and 10 diseases), storage of physiological disorders, and phenological models in 14 different crops.

CLIMEX Although not strictly the CLIMEX software phenology model uses some developmental requirements for risk assessment

DYMEX The DYMEX package aims to help ecologists overcome the computing difficulties associated with constructing simulation models, allowing them to build mechanistic, process-based models. DYMEX modeling software has been extended to better support spatially explicit simulations, including wind dispersal.

ECAMON Basic modeling platform which serves simulations and phenology production of European corn borer over study regions in the Czech Republic

HEAPS The Helicoverpa armigera and H. punctigera Simulation model (HEAPS) incorporates modules based on adult movement, oviposition, development, survival, and host phenology and estimates the population.

ILCYM Insect Life Cycle Modeling (ILCYM) software is a generic open-source computer-aided tool, which facilitates the development of phenology models and prediction of pest activity in specific agroecologies.

MORPH/ MORPH includes a suite of predictive computer models for HIPO use in fruit and vegetable crops. The software tool HIPPO is described that allows biologists to produce models that are biologically realistic without having to write complex computer programs.

NAPPFAST Web-based plant pest forecast modeling system, which links daily climate and historical weather data with biological models to produce customized risk maps for phytosanitary risk assessments.

NEWA The NEWA (Network for Environmental and Weather Application) is a web-based weather and pest reporting and forecasting system. There are over 20 Massachusetts locations that are reporting to this network performing forecasts and alerts for insect and disease pests of fruits and vegetables.

CAPS-PEST The Cooperative Agricultural Pest Survey (CAPS) provides TRACKER landscape information based on survey data which is available through the WWW to prevent the spread of pest

PRO_PLANT PRO_PLANT is a knowledge-based plant protection advisory system which supports fungicide and growthregulator consultations for cereal and sugar beet production. In addition it provides consultations on insecticide usage in rape and herbicide usage in corn.

University of California

Goodell et al. (1990)

USDA-APHIS-PPQ (Western Region) and the University of Wyoming

Computer Centre for Agricultural Pest Forecasting (CIPRA), Canada

Australia

INRA Forest Zoology Unit (http://www.hearne.com.au/ Software/DYMEX/News)

Institute of Agro-systems and Bioclimatology, Mendel University of Agriculture and Forestry Brno, Czech Republic

Australian Cotton Research Institute

Centro International de la Papa, Integrated Crop Management Division, Lima, Peru

UK Horticulture Research International

North Carolina State University, USA

Cornell University, New York State Integrated Pest Management Program

Plant Protection and Quarantine Division of the USDA Animal and Plant Inspection Services

Department of Computer Science in Agriculture at the University of Munster (DCSA-UMG) and Department for Plant Protection, Seed testing and
Branting et al. (1997), Hastings et al. (2010)

Bourgeois et al. (2008)

Sutherst et al. (1991, 1999)

Stephens and Denter (2005), Parry et al. (2011)

Trnka et al. (2007)

Dillon and Fitt (1990), Fitt et al. (1995)

Sporelder et al. (2009)

Phelps et al. (1999)

Magarey et al. (2007)

http://www.newa.cornell.edu/

http://pest.ceris.purdue.edu/

Visser et al. (1994) 
Table 1 (continued)

\begin{tabular}{|c|c|c|c|}
\hline Acronym & Main task, objectives, and services & Institution/location & Reference \\
\hline & & $\begin{array}{l}\text { Agriculture Research } \\
\text { (DPSAR) }\end{array}$ & \\
\hline RANTISMA & $\begin{array}{l}\text { RANTISMA (Real Agro-Net Topology and Insect Smart } \\
\text { Model Application) is a simple handling pilot software } \\
\text { which provides real-time pest forecasting through the } \\
\text { www for fruit orchards pest. }\end{array}$ & $\begin{array}{l}\text { RANTISMA.gr Open Agro Data } \\
\text { research consortium/Greece }\end{array}$ & $\begin{array}{l}\text { Damos and Karabatakis } \\
\text { (2013) }\end{array}$ \\
\hline RICEPEST & $\begin{array}{l}\text { RICEPEST is a multipest system model simulating yield } \\
\text { losses due to several rice pests (sheath blight, brown spot, } \\
\text { sheath rot, bacterial leaf blight, stem borers, brown plant } \\
\text { hopper, defoliating insects, and weeds) under a range of } \\
\text { specific production situations of tropical Asia. }\end{array}$ & $\begin{array}{l}\text { International Research Institute } \\
\text { (Philippines) }\end{array}$ & Willocquet et al. (2002) \\
\hline SAIFA & $\begin{array}{l}\text { The SAIFA (Sistema de Alerta e Información Fitosanitaria } \\
\text { Andaluz) is a web-based phytosanitary information and } \\
\text { alert system for integrated production of olive cultivation. }\end{array}$ & $\begin{array}{l}\text { Universidad de Almería, } \\
\text { Department of Computer } \\
\text { Science/Spain }\end{array}$ & Orellana et al. (2011) \\
\hline SIMLEP & $\begin{array}{l}\text { Temperature-driven decision support system (SIMLEP DSS) } \\
\text { for regional forecasting of Colorado potato beetle } \\
\text { (Leptinotarsa decemplineata) which consists of two } \\
\text { modules. SIMLEP } 1 \text { is a regional forecasting model for the } \\
\text { first occurrence of hibernating beetles and the start of egg } \\
\text { laying. SIMLEP } 3 \text { is a field-specific model which forecasts } \\
\text { the occurrence of the developmental stages. }\end{array}$ & $\begin{array}{l}\text { Central Institution for Decision } \\
\text { Support Systems and } \\
\text { Programmes in Crop } \\
\text { Protection/Germany, Austria, } \\
\text { western part of Poland }\end{array}$ & $\begin{array}{l}\text { Jorg et al. (2007), Kleinhenz } \\
\text { and Rossberg (2008), Kos } \\
\text { et al. (2009) }\end{array}$ \\
\hline SOYPEST & $\begin{array}{l}\text { SOYPEST is a web-based fuzzy expert system used to help } \\
\text { inexperienced farmers in pesticide use of their farms. The } \\
\text { first version of this system was introduced in } 1995 \text { in a } \\
\text { single-user form. The objective of SOYPEST is to provide } \\
\text { IPM decision support to the farmers through the Internet. } \\
\text { Later, the web-based fuzzy expert system is proposed in } \\
\text { the field of e-commerce. }\end{array}$ & $\begin{array}{l}\text { Computer Science Department } \\
\text { Faculty of IT Universiti Utara } \\
\text { Malaysia, India }\end{array}$ & Saini et al. $(1998,2002)$ \\
\hline SOPRA & $\begin{array}{l}\text { SOPRA is an hourly driven time delay distribution } \\
\text { phenological model, which is linked to a detailed web- } \\
\text { based decision support system which extends information } \\
\text { about the pest insects and registered plant protection } \\
\text { products. }\end{array}$ & $\begin{array}{l}\text { Agroscope Changins-Wädenswil } \\
\text { Research Station ACW/ } \\
\text { Switzerland and Bavaria } \\
\text { (Southern Germany) }\end{array}$ & Samietz et al. (2008) \\
\hline FuzzyXPest & $\begin{array}{l}\text { FuzzyXPest is proposed to provide information to farmers } \\
\text { and researchers through the Internet using the fuzzy expert } \\
\text { system. This system has been verified by Malaysia } \\
\text { Agriculture Research \& Development Institute. }\end{array}$ & $\begin{array}{l}\text { Malaysia Agriculture Research \& } \\
\text { Development Institute }\end{array}$ & Siraj and Nureize (2006) \\
\hline $\begin{array}{r}\text { UC-IPM } \\
\text { online }\end{array}$ & $\begin{array}{l}\text { The UC (University of California) IPM offers interactive } \\
\text { tools and models that are used to make pest management } \\
\text { decisions based on local site conditions and using weather } \\
\text { models and degree-days. }\end{array}$ & $\begin{array}{l}\text { University of California } \\
\text { Statewide IPM Program/USA }\end{array}$ & http://www.ipm.ucdavis.edu/ \\
\hline WIDDS & $\begin{array}{l}\text { The web-based intelligent disease diagnosis system } \\
\text { (WIDDS) is using the fuzzy logic approaches to provide } \\
\text { diagnosis particularly for oilseeds like soyabean, } \\
\text { groundnut rapeseeds, etc. which will help increase the } \\
\text { ability of the cultivators/extension workers/researchers in } \\
\text { decision making. }\end{array}$ & Soybean Research (ICAR) & Kohle et al. (2011) \\
\hline
\end{tabular}

or short message service, upon critical points in which the pest population is higher than a particular threshold and proceeds to particular applications-treatments. To boot, it may be entering the web interface, powered by Drupal and manual perform queries and view pest population status.

The PRO PLANT DSS The PRO PLANT decision support system is considered as one of the most advanced (Frahm et al. 1996; Johnen and Meier 2000). The decision support system PRO_PLANT was developed in
Nordrhein-Westfalen (DE) to help farmers to reduce the input of plant protection products. The system runs phenological models for six major pests and takes into account the number of adult pests, weather-based forecast, egg-laying periods, and larval development (Johnen et al. 2010; Johnen and von Richthofen 2011). Automatically collected regional meteorological data are transferred via the Internet and are used as an input source for the models to provide pest forecasts. The DSS provides a basis for treatment decisions and pesticide applications. 
Concluding, overall professionals in the agricultural domain, such as growers, extension agents, and researchers, can be helped through the role of web-based decision support systems in IPM. However, although most systems provide forecasting models that predict the likelihood of a pest or disease outbreak, each one has been developed to address specific needs. Most pest management decision support systems are applying a conventional remote sensing of climatic data, which is traditionally been used also in precision agriculture and can assist crop growers in determining when or if pesticides are needed (Seem 2001).

Besides extending pest risk information, which is delivered by most systems, some others provide intuitive images representing epidemic risks and other information that may facilitate dissemination and understanding of risks to guide decision making on rational pest management (Fernandes et al. 2011). Moreover, despite that in most cases the software is freely accessible through the web, there are representatives in which specific registration is demanded.

\section{Challenges and constrains of decision support systems}

Apart from the formal description of the basic principles that are practiced to incorporate pest and disease models into webbased decision support systems for IPM, there are also some challenges and constrains that are be worthy to be discussed.

Pest and disease models are brief mathematical descriptions of data and per se have limited applicability. Still, easy handling of computer scripts and associated software, which runs the models, facilitates significantly the simulation of population dynamics and offers practical information outlets in IPM (Prasad and Prabhakar 2012). Some of the cited webbased IPM DSS has lab-derived predefined models and employs actual time set of input data and afterwards starts to operate via web interface to provide the related information services to the end user. Here, the algorithms play a significant role since pest and disease knowledge is represented in the form of logical operations. These simulations may be comprised in an information system and provide practical application and mechanization of decision support, for example, to forecast population dynamics and send warnings to farmers if the pest reaches specific thresholds and to suggest management activities. Moreover, such prediction schemes may be extended to include more variables and information, such as weather forecasts and economics, in order to select the most cost-effective management actions (Strand 2000).

Nevertheless, there are also some concerns, either ecological or technical, when developing, enforcing, and evaluating the functionality of a DSS for praxis. Pest and disease monitoring data, along with complementary weather data, are still crucial to validate the functionality of pest forecast models and improve simulations and warnings for operational use. Most of the earlier models, for instance, failed to get into consideration the variation between individual insects in their rate of maturation, which is responsible for the spread of activity of a pest (Wagner et al. 1984a, b). This hindrance has been acknowledged by earlier studies, and therefore, efforts have been induced to count rates as random variables (Phelps et al. 1993) instead of treating rate summation as a deterministic quantity. Other factors, which bias forecast prediction, are that most species exhibit seasonal life cycles that include resting phase and are affected by other factors, which are seldom taken into consideration. Resting phases are for instance diapause or aestivation, while other factors may include selfregulation and predation. Additionally, a restricted temperature-driven model does not often go to reliable forecasts because of bias in databases due to ecological processes such as short-range dispersal, overwintering behavior, colonization patterns, and age-specific mortality including inter- and intraspecific competition. Nevertheless, if a DSS is proven reliable after experimental evaluation, it provides a means of accurate timing of pesticides and initiation of pest management tactics, and computer-based technology may be utilized to carry out an IPM plan.

Some other constraints are of technological nature, and although several decision tools for pest management are available (Norton and Mumford 1993), not all of them have been translated into the routine decision-making systems, which can justify the marginal costs of going forward to maintain and updating the scheme. Another constraint in the use of the referred DSS is the need to be combined with real-time and often scarce, weather variables in a complementary and automatic manner. The problem may be even more complicated especially that environmental variables can be significantly different from one region to an adjacent one and that it is virtually impossible to store data from all situations. The PRO_PLANT advisory system, for example, although it has been intensively tested in the period between 1991 and 1995 by plant protection advisors and farmers all over Germany, its utilization in some European countries has posed some difficulties. This was mostly due to the lack of weather data, their availability in different formats, and the different law structures and registration about pesticides. Nevertheless, the system per se has been successfully installed and used in many countries in mainland Europe (Johnen et al. 2006) and it is now also freely available to UK growers via the BeyerCrop science website for pollen beetle management (Johnen et al. 2006; Johnen and von Richthofen 2011).

In some cases, the required data are not only large in amount but also come from multidisciplinary sources, and the same situation exists for related decision support tools. Such complexity along with emergent web engineering sciences, which are using ontologies and artificial intelligence, 
brings challenges to the design and implantation of web-based decision support systems (Zhang and Goddard 2007). Actually, the evolution, application, and operational testing of the DSS are an interdisciplinary research theme, which requires the integration of different methodologies to solving pest and disease management problems at the field level and it continuous advancement.

However, DSS or other web-related prediction schemes have thorough information description useful for IPM. A component of pest forecasting information may include biological, environmental, economic, or other outputs to analyze the most effective management actions, based on acceptable control levels, sustainability, and further assessment of economic or other risks (Strand 2000). Thus, DSS in IPM is a potential tool for synthesizing the available bioeconomic information and knowledge of population dynamics of pests in agroecosystems and natural habitats.

Such kind of Internet and network-based applications in agriculture have been much emphasized in the past decade (Baharudin 2000) and may play an even more important role in considering that most web applications are directly accessible via $4 \mathrm{G}$ smart phones. For instance, the corn disease remote diagnostic system is supported by a database containing information for the identification of 63 diseases. The system can be used as a diagnostic tool for farmers; it can also function as a tutorial system for students (Xinxing et al. 2012). Furthermore, the widespread use of network interfaces with PHP dynamic script solutions takes into account the design of interactive user-friendly interfaces that accommodate both producers in the subject as well as researchers.

On the other hand, the potential incorporation of machinereadable knowledge capacities into specific databases like MySQL in an IPM DSS permits to query expansion and semantic inference. In this context, research and development in knowledge acquisition of agrodatabases and related modeling applications, using artificial intelligence to cluster and relate data, is likewise rising (Prasad et al. 2006; Patil et al. 2009; Zhang et al. 2008). In particular, ontology web programming (OWL) and artificial intelligence (AI), available only during the last years because of emergent web-3 technology, provide new means of knowledge representation. Actually, OWL programming is a breakthrough in computer science, and it is anticipated that they will modify all current web applications, including the attributes and use of decision support systems in agriculture. Agricultural ontologies, or linked data, build the use of objects and information. These objects may include descriptive data, scientific names, icons, and their properties, which are primarily applied for classification purposes and semantic inference (Koenderink et al. 2005; Zheng et al. 2012; Sun et al. 2013). The most representative successful model is probably the AGROVOC thesaurus (http://aims. fao.org/standards/agrovoc/about). AGROVOC is a controlled vocabulary, covering all regions of interest of the
Food and Agriculture Organization (FAO) of the United Nations and the delegation of the European communities, including food, nutrition, farming, fisheries, forestry, environment, etc. It is published by FAO and edited by a community of experts and the related Advanced Ontology Service (AOS) project was endeavored (Soergel et al. 2004; Sini 2009). Thus, for IPM DDS, the potentials to provide to the end user information retrieval services work using cognitive approaches and stress the knowledge in information bases as separate components. This is a major advantage because additional changes in knowledge and updates do not change the whole structure of the system. Another advantage of such kind of DSS is reasoning capability; the system explains reasons for arriving at a particular decision, a process that is closer to human cognitive approaches for problem solving (Yelapure and Kulkarni 2012).

\section{Vision of the future of decision support system}

Since IPM involves the coordinate use of all available and control tactics, the technological aspects of synthesis and knowledge integration have been tried from many different starting points in the past. For some earlier efforts in developing a decision support system in plant protection, for example, refer to Coulson and Saunders (1987), Stone and Saarenma (1988), Coulson et al. (1989), and Zalom and Strand (1990). Most of these earlier works developed pest simulation programs that are in apposition to project actual pest population dynamics useful for decision making. Nevertheless, only more recent technological advances provided a robust means of computerized implementation of IPM.

Moreover, it is expected that emergent technologies in information science and population modeling will influence the development and design of future DSS. Researchers have recognized that ontology web programing is one of the major success stories of the third generation semantic web. Scientist and national authorities around the world already value the potentials and benefit that web-based decision support applications and services may bring in general in the agricultural domain and in particular in pest management. Thus, we may expect in the short future a more reusable and interoperable fashion exchange of agrodata that will among others contribute to the development of easy handling of pest modeling and extension applications.

We hold that technical issues, such as minimizing the requirements for publishing data, the interoperability to data consumers, and the increase in computer processing capacity, are more likely to be overcome (Lokers et al. 2014). Moreover, there is also an issue concerning the availability of free scientific measures data and free public services for decision support systems. For instance, although there are several institutional web applications that provide farmers free support, 
there are also a comprehensive number of private DSS services and it is expected that they will increase in the future.

For small cooperatives and producers, such applications will strengthen the role of decision support for integrated pest management. Expansion in the use of web-based applications will result in decision support products and integrated pest management services that are advantageous than those produced by autonomous and manual efforts. Decision support systems used in the plant protection domain applications will result in minimizing overhead costs such as telephone, printing, and postal along with costs of unnecessary pesticide treatments. Yet, traditional farmers take it hard to adopt even minimal cost web applications in plant protection because they are most often not familiarized with current technologies (Deraman and Shamsul Bahar 2000). Additionally, because middle and older age farmers are reluctant to make changes to their practices, which they are very comfortable doing, future decision support systems should be probably adopted by younger and more educated farmers (Dillon and Fitt 1990).

Another factor which may affect future adoption of DSS is the bad perception for new technologies by farmers. Particularly, low adoption of DSS may be related to the weak belief on ensuring high yield of new technology (Chi and Yamada 2002). Especially for plant protection, it is important to evaluate the performance and field success of the pest management decision support system to be further adopted. Actually, the performance of several pest decision support systems has not been fully evaluated to be broadly used. Although meteorological datasets can now be provided in real time at very high rates of up to once every few seconds, the accuracy of data depends on the reliability of the installed measuring instruments of weather stations. On the other hand, population processes are multifaceted and most pest models are oversimplifications, which often ignore other variables. Moreover, most of the successful DSS are commercial and this makes knowledge sharing difficult. Thus, besides the reliability of the climatic input data and the function of simulation algorithms, the degree of success with which the DSS accomplishes a task depends on the validity of the underlying population models as well as the correctness of their implementation. As a result, potential underutilization of some decision support systems is likely due to both perception and technical constraints that have not been addressed adequately during development and implementation phases (Knight 1997; Gent et al. 2011). Therefore, it is anticipated that the incorporation of reliable IPM recommendations may be basic means to increase the adoption of DSS by farmers. At the same time, any DSS should be low cost, user friendly, and relevant to recent IPM tools, to provide a set of real-time management options that a farmer can apply (Nguyen et al. 2006). Thus, the role of DSS in IPM will increase in the future, if it is reliable, has suitable attributes, and reduces pest management costs.
From a technological standpoint, future decision support systems may contain information of all crop management options toward precision farming and not only pest management. For instance, farmers possess smart phones with the capability to access the Internet through wireless connections and have access to geographical information data (GIS), which possess potential for several applications (Singh et al. 1993). The implementation of such applications is accelerating, while remote sensing and cloud computing provide additional means to gather real-time precise field data. For instance, GIS data on weather, land use, hydrography, soil, and pests can be captured in digital maps and combined with field data input collections to create models not only for pest management but also for crop, soil, and integrated fruit production system evaluation, to field and region-scale reports and schemes for precise decisions and advisories (Bregt 1997; Strickland et al. 1998). Moreover, as part of accurate pesticide timing, decision support systems merged with GIS technologies may provide information upon site-specific management of pests.

Finally, semantic knowledge representation tools that emerge may create entirely new capabilities in decision support systems (Kamalak and Hemalatha 2012). The development of agro-ontologies and application of related artificial intelligence techniques may become an absolute demand for local, regional, and area-wide management of multidimensional agrodatabases and information retrieval.

\section{Conclusion}

Crop pest management is a highly challenging problem and may yield potential losses of up to $50 \%$ before harvest if not handled timely. Thus, there is a need of extension warning programs and the use of interdisciplinary technologies for sustainable pest control. In this review, knowledge has been provided with different sources including published literature. Efforts were made to understand the role of decision support systems for integrated pest management and to describe the basics that are practiced to incorporate pest and disease models into IPM. Moreover, examples on how new web technologies, including ontology web programming, can be used to develop a decision support system for integrated pest management are also presented. Instances of pest forecasting tool and IPM decision support systems are also discussed to popularize the use of current computer-aided pest management applications.

Since IPM traditionally is founded on a system approach and involves low energy influxes, it provides a convenient support for sustainable agriculture. Particularly, the appropriate and optimal combination of control measures is required to be applied in a rational manner to guarantee cost-effective and environmental-friendly pest management (Bajwa and Kogan 2000). Due to imperfect and involved uncertainty of climate 
effects on pest population development, it is virtually impossible to make predictions based only on monitoring and sampling. Additionally, early plant disease growth is often characterized by the absence of symptoms, which appear quite later, in periods where crop damage is irreversible. As a result, the development of decision support systems for pest management is an absolute necessity, which will allow farmers to apply in time various pest control actions. Additionally, once a decision support system has been set up, it forms a basis to be extended including most crop management actions such as irrigation, fertilization, and so on.

However, the transition from manual-based toward computer-aided decision support is a challenging task that is mediated through the development of pest forecasting algorithms. In its simplest form, they serve as small computer programs, or software, which aim to combine climatic, threshold pest developmental data and population models and to initiate pest warnings through logical relations. The algorithms that have been presented in the current work have been developed to meet specific needs although can also serve as typical instances. Forecasting algorithm, which runs through a personal computer, can be merged with current web technologies toward the development of a dynamic forecasting application or, preferably, toward a decision support system.

Since 1980, there has been increased interest in developing forecasting methods as well as in promoting an effective warning system for pests and diseases. Nowadays, considering that the www is the fasted growing medium, it is expected that agrodata-fused information technology will play key roles in sustainable agriculture and particularly in the automaticity of real-time pest management, acquisition, and dissemination of new knowledge and technology in IPM.

Ontology web programing is an emergent new technology feasible due to the improvement of the overall framework and potentials of the current www. The major principle of improving pest ontologies is to gather data together in a manner that provides free accessibility and comprises potentials for several applications. The development of ontologies results in the dispersion of free information easy reachable and available for individuals, companies, state authorities, research centers, universities, and many other interested parties and comprises potentials for broader data exploitation and rational economic development.

However, it is essential to state that such novel technologies are accessible only during the last 5 years and because of emergent web technologies. This is probably the main reason why the classification of concepts for pest ontologies is rare. One additional reason is that the development of decision support systems for IPM, as well as related ontologies, is of a multidisciplinary nature and such a task enables the collaboration of expertise from different scientific fields. Another obstacle is to raise funds that can support not only the recruitment of high-caliber researchers and experts but also to support and evaluate the functionality of the system after its completion.

Based on the literature review, there are several decision support systems and pest forecasting applications that have been developed. However, only few of them are truly decision support systems by the sense that they provide user interaction and operate daily on real time providing pest warnings and related management options. Two of the earliest and most successive examples are the forecasting tools SOPRA and PRO_PLANT which move beyond simple IPM information retrieval and support the users in the decision management process. However, there are challenges concerning how these systems may be extended to include more crop management options toward precision farming and sustainable agriculture.

In addition, such success stories may serve as paradigms for the development of national- and country-level decision support systems for other countries as well. However, despite the fact that there have been several crop-specific technical guidelines that have been developed, they cannot be implemented due to the time-sensitive nature of most management actions. Thus, available pest management options, although they provide a rigorous foundation for development of sustainable utilization of pesticides in the $\mathrm{EU}$, are implemented only in those countries which operated such systems.

Consequently, indispensable for implementing IPM programs in reality is to furnish real-time data, which support pest management advisors and farmers at the field level to successfully apply IPM tools and to maximize the potential of their control activities. Moreover, pest knowledge exchange and development of interlinked data networks can be performed using current www infrastructures with relatively low costs. Such structures may provide collaboration opportunities and reduce time spent and redundant efforts for wide scale pest management. Using standard web infrastructure makes it feasible to further provide a decentralized but collaborative international (common) cloud environment for the development and maintenance of information that can occur among distant and dispersed developers and institutions.

It is believed that the interest on IPM decision support systems as technological solution for sustainable pest management will increase and be an absolute need for rational management agrosystems. Moreover, it is also anticipated that future decision support system will be merged with ontology-based knowledge representation to cope with huge datasets to provide integrated robust decision support solutions.

Acknowledgments The author would like to convey his thanks to the editor and four anonymous reviewers for their valuable suggestions and commentaries, which have improved the MS. 


\section{References}

Abdullah A, Hussain A (2006) Data mining a new pilot agriculture extension data warehouse. J Res Pract Inf Tech 38:229-249

Agrios GN (2005) Plant pathology, 5th edn. Elsevier, London

Altieri MA (1987) Agroecology: the scientific basis of alternative agriculture. Westview, New York, 185pp

Altieri MA, Nicholls C I (2000) Agroecology in action. Indigenous and modern approaches to IPM in Latin America. ESPM Division of Insect Biology, University of California, Berkeley, USA. http:// nature.berkeley.edu/ miguel-alt/indigenous_and_modern approaches.html. Accessed 18 May 2015

Amano H (2001) Species structure and abundance of invertebrate natural enemies in sustainable agroecosystems. In: Shiyomi M, Koizumi H (eds) Structure and function in agroecosystem design and management. CRC, New York, pp 167-182

Andrade-Piedra J, Forbes G, Shtienberg D, Grünwald NJ, Chahón MG, Taipe V et al (2005) Qualification of plant disease simulation model: performance of the LATEBLIGHT model across a broad range of environments. Phytopathology 95:1412-1422. doi:10.1094/ PHYTO-95-1412

Asher, HB (1984) Causal modeling. Sage University paper series on quantitative applications in the social sciences, 07-003. Sage, Newbury Park

Athanasiadis IN, Rizzoli AE, Jansen S, Andersen E, Villa F (2009) Ontology for seamless integration of agricultural data and models. In: Sartori F, Sicilia MA, Manouselis N (eds) 3rd International conference on metadata and semantics research (MTSR'09). Springer. pp. $282-293$

Backoulou GF, Elliott NC, Royer TA, McCornack BP, Giles KL, Pendleton BB et al (2014) Web-based decision support system for managing panicle caterpillars in sorghum. Crop Manage. doi:10. 2134/CM-2014-0020-MG

Baharudin SA (2000) Preservation of culture in an Internet worked world. Rahim RA, John KJ (eds) Access, empowerment and governance in the information age. Building Knowledge Societies Series, volume I: NITC (Malaysia) Publ: $68-75$

Bajwa WI, Kogan M (2000) Database management system for Internet IPM information. In: Shenk M, Kogan M (eds) IPM in Oregon: achievements and future directions. Oregon State University, Corvallis, p 227

Bajwa WI, Kogan M (2002) Compendium of IPM definitions (CID)what is IPM and how is it defined in the worldwide literature? IPPC Publication No. 998, Integrated Plant Protection Center (IPPC), Oregon State University, Corvallis, OR 97331, USA

Bajwa WI, Coop L, Kogan M (2003) Pest management (IPM) and Internet-based information delivery systems. Neotropical Entomology 32:373-383. doi:10.1590/S1519-566X 2003000300001

Bange MP, Deutshcer SA, Larsen et al (2004) A handheld decision support system to facilitate improved insect pest management in Australian cotton systems. Comp Electron Agric 43:131-147. doi: 10.1016/j.compag.2003.12.003

Barlet BR (1956) Natural predators. Can selective insecticides help to preserve biotic control? Agric Chem 11:42-44

Batchelor WD, McClendon RW, Adams DB, Jones JW (1989) Evolution of SMARTSOY: an expert system for insect pest management. Agr Syst 31:67-81

Beck SD (1983) Insect thermoperiodism. Ann Rev Entomol 28:91-108. doi:10.1146/annurev.en.28.010183.000515

Beck HW, Jones P, Jones JW (1989) OYBUG: an expert system for soybean insect pest management. Agric Syst 31:32-37. doi:10. 1016/0308-521X(89)90091-7
Bery JS (1995) Computer models in integrated pest management: a case study of the grasshopper integrated pest management project. J Agric Entomol 12:229-240

Boller EF, Avilla J, Jörg E, Malavolta C, Wijnands F, Esbjerg P (2004) Integrated production: principles and technical guidelines, 3rd ed. IOBC WPRS Bulletin, 27, pp 1-30

Bouma E (2004) Decision support systems used in the Netherlands for reduction in the input of active substances in agriculture. EPPO Bull 33:461-466. doi:10.1111/j.1365-2338.2003.00680.x

Bourgeois G, Plouffe D, Chouinards G et al (2008) The apple CIPRA network in Canada: using real-time weather information to forecast apple phenology, insect diseases and physiological disorders. Acta Horticult 803:29-34

Branting LK, Hastings JD, Lockwood JA (1997) Integrating cases and models for prediction in biological systems. AI Appl 11:29-48

Bregt AK (1997) GIS support for precision agriculture: problems and possibilities. Ciba Found Symp 210:1730179. doi:10.1002/ 9780470515419.ch11

Brown JH (1984) On the relationship between abundance and distribution of species. Am Nat 124:255-279

Cairns DM, Lafon CW, Andrew GB, Waldron JD, Tchakerian M, Coulson RN (2008) Simulation modeling as a tool for understanding the landscape ecology of southern pine beetle infestation in southern Appalachian forest. Geogr Compass 2(3):580-599. doi:10.1111/j. 1749-8198.2008.00098.x

Caracciolo C, Stellato A, Morshed A et al. (2012) The AGROVOC linked dataset. Editors: Pasa; Hitzler, Kno.e.sis Centre: Wright State University, Dayton, Ohio, USA; Krzysztof Janowics, University of California, Santa Barbara, California, USA. http://www.semanticweb-journal.net/system/files/swj274_1.pdf. Accessed 18 May 2015

Carlson GA, Headley JC (1987) Economic aspects of integrated pest management threshold determination. Plant Dis 71:459-462

Chakrabarti S, van der Berg M, Dom B (1999) Focused crawling: a new approach to topic-specific web resource discovery. Computer Networks 31:1623-1640. doi:10.1016/S1389-1286(99)00052-3

Cheke R, Tratalos JA (2007) Migrations, patchiness and population processes illustrated by two migrant pest. Bioscience 57:145-154. doi: 10.1641/B570209

Chi TTN, Yamada R (2002) Factors affecting farmers' adoption of technologies in farming systems: a case study in OMon district, Can Tho province, Mekong Delta. Omonicre 10:94-100. doi:10.5539/jas. v4n2p139

Coulson RN, Saunders MC (1987) Computer-assisted decision making as applied to entomology. Ann Rev Entomol 32:415-437. doi:10.1146/ annurev.en.32.010187.002215

Coulson N, Saounders C, Loh DK et al (1989) Knowledge systems environment for integrated pest management in forest landscapes: the southern pine beetle. Bull Entomol Soc Am 34:26-32. doi:10.1093/ besa/35.2.26

Cowell L, Smith B (2010) Infectious disease ontology. In: Sintchenko V (ed) Infectious disease informatics. Springer, New York, pp 373 395

Croft BA, Michels MF, Rice RE (1980) Validation of a PETE timing model for the oriental fruit moth in Michigan and central California (Lepidoptera: Olethreutidae). Great Lakes Entomol 13: 211-217

Cross, Dickler (1994) Guidelines for integrated production of pome fruits in Europe: IOBC technical guideline III. IOBC/WPRS Bull 17:1-8

Damos P (2013a) Current issues in integrated pest management of Lepidoptera pest threats in industrial crop models. Nova Science, New York, pp 45-86

Damos (2013b) Semantics and emergent web3 technologies: modern challenges for integrated fruit production systems towards internationalization. Integrated protection of fruit crops. IOBC-WPRS Bull 91:133-142 
Damos P, Karabatakis S (2013) Real time pest modelling through the world wide web: decision making from theory to praxis. Integ Protec fruit crops IOBC-WPRS Bull 91:253-258

Damos P, Savopoulou-Soultani M (2008) Temperature dependent bionomics and modeling of Anarsia lineatella in the laboratory. $\mathrm{J}$ Eco Entomol 101:1557-1567. doi:10.1603/0022-0493(2008)101 [1557:TBAMOA]2.0.CO;2

Damos P, Savopoulou-Soultani M (2010) Development and statistical evaluation of models in forecasting major lepidopterous peach pest complex for integrated pest management programs. Crop Prot 29: 1190-1199. doi:10.1016/j.cropro.2010.06.022

Damos P, Savopoulou-Soultani M (2011) Microlepidoptera of economic significance in fruit production: challenges, constrains and future perspectives for integrated pest management. In: Caterruccio $\mathrm{R}$ (ed) Moths: types, ecological significance and control methods. Nova Science, New York, pp 75-113

Damos P, Savopoulou-Soultani M (2012) Temperature-driven models for insect development and vital thermal requirements. Psyche. doi:10. $1155 / 2012 / 123405$

Damos P, Oikonomou M, Bratsas Ch, Antoniou I (2012) Agrosemantics knowledge representation via open linked data (OLD) cloud: a case study in integrated crop production. Proceedings of ESDO Mibes Congr., 25-27, Mai 2012, pp 106-118 (abstract in Greek) ISBN: 978-960-9510-05-9.

d'Aquin M et al (2008) Toward a new generation of semantic web applications. IEEE Intell Syst 23:20-28. doi:10.1109/MIS.2008.54

Dent D (1995) Integrated pest management. Chapman and Hall, London, 1994

Deraman AB, Shamsul Bahar AK (2000) Bringing the farming community into the Internet age: a case study. Inf Sci 3:5-10

Dillon ML, Fitt GP (1990) HEAPS: a regional model of Heliothis population dynamics. In: Proceedings of the Fifth Australian Cotton Conference, 8-9 August, Broadbeach, Queensland, Australia. Australian Cotton Grower's Research Association, Australia, pp. 337-344

Don Wauchope R, Ahuja LR, Arnold JG, Bigner R, Lowrance R, van Genuchten MT et al (2003) Software for pest-management science: computer models and databases from the United States Department of Agriculture-Agricultural Research Service. Pest Man Sci 59:691698. doi:10.1002/ps.682

Duggal N, Siddiqi Z (2008) Providing decision making analytical tools to IPM managers through we based: electronic pest monitoring, and pesticide use reporting system. In: Robinson WH, Bajomi D (eds) Proceedings of the sixth international conference on urban pests, 2008 Printed by OOK-Press Kft., H-8200 Veszprém, Pápai út 37/ a, Hungary.

Ehler LE (2006) Integrated pest management (IPM): definition, historical development and implementation, and other IPM. Pest Manag Sci 62:787-789. doi: $10.1002 / p s .1247$

Elliott NC, Royer TA, Giles KX, Kindler SD, Porter DR, Elliott DT, Waits DA (2004) A web-based decision support system for managing greenbugs in wheat. Crop Manag. doi:10.1094/CM-2004-1006$01-\mathrm{MG}$

Ferguson AW, Nevard LM, Clark SJ, Cook SM (2015) Temperatureactivity relationships in Meligethes aeneus: implications for pest management. Pest Manag Sci 71:459-466. doi:10.1002/ps.3860

Fernandes JMCF, Pavan W, Sanhueza RM (2011) SISALERT — a generic web-based plant disease forecasting system. In: Salampasis M, Matopoulos A (eds) Proceedings of the international conference on information and communication technologies for sustainable agri-production and environment (HAICTA 2011), Skiathos, 8-11 September, 2011

Fitt GP, Dillon ML, Hamilton JG (1995) Spatial dynamics of Helicoverpa populations in Australia: simulation modeling and empirical studies of adult movement. Comp Elect Agric 13:177-192. doi:10.1016/ 0168-1699(95)00024-X
Flint ML, van den Bosch R (1981) Introduction to integrated pest management. Plenum, New York

Frahm J, Volk T, Johnen A (1996) Development of the PRO_PLANT decision-support system for plant protection in cereals, sugarbeet and rape. EPPO Bull 26:609-622. doi:10.1111/j.1365-2338.1996. tb01504.x

Garret KA, Forbes GA, Savary S, Skelsey P, Sparks AH, Valvida C et al (2011) Complexity in climate change impacts: an analytical framework for analysis of effects mediated by plant disease. Plant Pathol 60:15-30. doi:10.1111/j.1365-3059.2010.02409.x

Gent DH, De Wolf E, Pethybridge SJ (2011) Perceptions of risk, risk aversion, and barriers to adoption of decision support systems and integrated pest management: an introduction. Phytopathology 101: 640-643. doi:10.1094/PHYTO-04-10-0124

Goodell PB, Richerd EP, Thomos A, Kerby (1990) CALEX/cotton: an integrated expert system for cotton production and management. Calif Agric 44:18-21

Goumopoulos Ch., Kameas A D (2009) An ontology-driven system architecture for precision agriculture applications. Int. J. Metadata, Semantics and Ontologies 4:72-84. doi: 10.1504/IJMSO.2009. 026256

Hannon B, Ruth M (2009) Dynamic modeling of diseases and pests. Springer, New York. doi:10.1007/978-0-387-09560-8

Hastings JD, Latchininsky AV, Schellb SP (2010) CARMA: scalability with approximate-model-based adaptation. In: Yang A, Voinov A, Rizzoli, Filatova $\mathrm{T}$ (eds) International congress on environmental modelling and software modelling for environment's sake, fifth biennial meeting, Ottawa, Canada David A. Swayne, Wanhong http:/ www.iemss.org/iemss2010/index.php?n=Main.Proceedings. Accessed 18 May 2015

Haverkort AJ, Top JL (2010) The potato ontology: delimitation of the domain, modelling concepts, and prospects of performance. Potato Res 54:119-136. doi:10.1007/s11540-010-9184-8

Hearn AB, Bange MP (2002) SIRATAC and CottonLOGIC: persevering with DSSs in the Australian cotton industry. Agr Sys 74:27-56

Higley LG, Pedigo LP, Ostlie KR (1986) DEGDAY: a program for calculating degree-days, and assumptions behind the degree-day approach. Environ Entomol 15:999-1016. doi:10.1093/ee/15.5.999

Huang Y, Lan Y, Westbrook JK, Hoffman WC (2008) Remote sensing and GIS applications for precision area-wide pest management: implications for homeland security. Geospat Tech Homel Secur 94: 241-255. doi:10.1007/978-1-4020-8507-9 12

Jacobs I, Walsh N (2004) Architecture of the world wide web, volume one-W3C recommendation. http://www.w3.org/TR/webarch/. Accessed 18 May 2015

Johnen A, Meier H (2000) A weather-based decision support system for managing oilseed rape pests. Proceedings of the British Crop Protection Conference, Pest and Diseases, Brighton, November 2002, pp13-16

Johnen A, von Richthofen JS (2011) The decision-support system proPlant expert: a computer-based tool for integrated pest management used in Europe. Bull IOBC/WPRS 96:99-105

Johnen A, Williams IH, Ferguson AW, Büchs W, Klukowski Z, Luik A, Nilsson C, Ulber B (2006) MASTER: validation of existing phenological models of the proPlant DSS for key pests in winter oilseed rape in different climatic areas in Europe and prospects for IPM. International symposium on integrated pest management in oilseed rape. Göttingen, Germany. BCPC, Hampshire http://toc. proceedings.com/00287webtoc.pdf. Accessed May 2018

Johnen A, Williams IH, Nilsson C, Klukowski Z, Luik A, Ulber B (2010) The proPlant decision support system: phenological models for the major pests of oilseed rape and their key parasitoids in Europe. In: Williams IH (ed) Biocontrol-based integrated management of oilseed rape pests. Springer, Dordrecht, pp 381-403

Jones JW (1989) Integrating models with expert systems and data bases for decision making. In: Weiss A (ed) Climate \& agriculture- 
system approaches to decision making, Charleston Sc 5-7 March 1989, pp 194-211

Jonew VP, Brunner JF, Grove GG, Petit B, Tangen GV, Jones WE (2010) A web based decision support system to enhance IPM programs in Washington tree fruit. Pest Manag Sci 66:587-595. doi:10.1002/ps. 1913

Jorg E, Racca P, Preib U et al (2007) Control of Colorado potato beetle with the SIMPLEP decision support system. EPPO Bull 37:353358

Kamalak P, Hemalatha K (2012) Agro Genius: an emergent expert system for querying agricultural clarification using data mining technique. Res Invent Int J Eng Sci 1:34-39

Karabatakis S, Damos P (2013) Supporting integrated pest management using open data networks and information technology through the world wide web. In: Plant-insect ecosystems (P-IE) section symposium: global community-driven linked data for integrated pest management, pest risk analysis and biodiversity conservation through the world wide web. ESA 60th Annual meeting, Nov 11-14, Knoxville Tennessee, USA

Kaundal R, Kapoor AS, Raghava GPS (2006) Machine learning techniques in disease forecasting: a case study on rice blast prediction. BMC Bioinformatics. doi:10.1186/1471-2105-7-485

Khaliq A, Javed M, Sohail M, Sagheer (2014) Environmental effects on insects and their population dynamics. J Entomol Zool Stud 2:1-17

Kleinhenz B, Rossberg D (2008) Structure and development of decisionsupport systems and their use by the State Plant Protection Services in Germany. EPPO Bull 30:93-97. doi:10.1111/j.1365-2338.2000. tb00858.x

Knight JD (1997) The role of decision support systems in integrated crop production. Agric Ecosyst Environ 64:157-163

Knight JD, Cammel ME (1994) A decision support system for forecasting infestations of the black bean aphid, Aphis fabae Scop., on springsown field beans, Vicia faba. Comp Electr 10:269-279. doi:10. 1016/0168-1699(94)90046-9

Koenderink NJJR, Top JL, Van Vliet LJ (2005) Expert-based ontology construction: a case study in horticulture. In: Proceedings of 16th international workshop on database and expert systems applications (DEXA'05), 2005. doi: 10.1109/DEXA.2005.87 DOI:10.1109/ DEXA.2005.87\#blank

Kohle S, Kamal R, Saini HS, Gupta GK (2011) A web-based intelligent disease-diagnosis system using a new fuzzy-logic based approach for drawing the inferences in crops. J Comp Electron Agric 76:1627. doi:10.1016/j.compag.2011.01.002

Kontodimas DC, Eliopoulos PA, Stathas GJ, Economou LP (2004) Comparative temperature-dependent development of Nephus includens (Kirsch) and Nephus bisignatus (Boheman) (Coleoptera: Coccinellidae) preying on Planococcus citri (Risso) (Homoptera: Pseudo-coccidae): evaluation of a linear and various non-linear models using specific criteria. Environ Entomol 33:1-11. doi:10. 1603/0046-225X-33.1.1

Kos K, Tschope B, Jorg E, Trdan S (2009) Testing the suitability of SIMLEP decision support system for the protection of potato against Colorado potato beetle (Leptinotarsa decemplineata [Say], Coleoptera, Chrysomelidae) in Slovenia. Act Agric Slov 93:93-014

Lefebvre M, Langrel SRH, Gomez-y-Paloma S (2015) Incentives and policies for integrated pest management in Europe: a review. Agron Sustain Dev 35:27-45. doi:10.1007/s13593014-0237-2

Lewis WJ, van Lentern JC, Phatak SC, Tumlinson JH (1997) A total system approach to sustainable pest management. PNAS 94: 12243-12248

Liao SH (2005) Expert system methodologies and applications - a decade review from 1995 to 2004. Expert Syst Appl 28:93-103. doi: 10.1016/j.eswa.2004.08.003
Lichtfouse E, Navarrete M, Debaeke P et al (2009) Agronomy for sustainable agriculture. A review. Agron Sustain Dev 29:1-6. doi:10. 1051/agro:2008054

Logan JA, Weber LA (1989) Population model design system (PMDS): user's guide. Department of Entomology, Virginia Polytechnic Institute and State University, Blackburg, Virginia.

Logan JA, Wollkind DJ, Hoyt SC, Tanigoshi LK (1976) An analytic model for description of temperature dependent rate phenomena in arthropods. Environ Entomol 5:1133-1140. doi:10.1093/ee/5.6. 1133

Lokers R, Konstantopoulos S, Stellato A, Knapen R, Janssen S (2014) Design innovative linked open data and semantic technologies for agro-environmental modeling. In: Ames DP, Quinn NWT, Rizzoli AE (eds) Proceedings of the 7th international congress on environmental modelling and software 2014, June 15-19, San Diego, California, USA. ISBN: 978-88-9035-744-2

Magarey PA, Wachtel MF, Weir PC, Seem RC (1991) A computer-based simulator for rationale management of grapevine downy mildew Plasmopara viticola. Plant Prot Q 6:29-33

Magarey RD, Fowler GA, Borchedt DM et al (2007) NAPPFAST: an Internet system for the weather based mapping of plant pathogens. Plant Dis 91:365-345. doi:10.1094/PDIS-91-4-0336

McBratney A, Whelan B, Ancev T, Bouma J (2005) Future directions of precision agriculture. Precis Agric 1:7-23. doi:10.1007/s11119-0050681-8

McRoberts N, Hall C, Madden LV, Hughes G (2011) Perceptions of disease risk: from social construction of subjective judgments to rational decision making. Phytopathology 101:654-665. doi:10. 1094/PHYTO-04-10-0126

Nguyen NC, Wegener M, Russel I (2006) Decision support systems in Australian agriculture: state of the art and future development. AFBM J 4:15-21

Nietschke BS, Magarey RD, Borchert DM et al (2009) A developmental database to support insect phenology models. Crop Prot 26:14441448

Norton GA, Mumford JD (1993) Decision tools for pest management. $\mathrm{CAB}$ International, Oxford

Nutter FW (2007) The role of plant disease epidemiology in developing successful integrated disease management programs. In: Clancio A, Mukerji G (eds) General concepts in integrated pest and disease management. Springer, Dordrecht, pp 45-79

Nutter FW, Parker JK (1997) Fitting disease progress curves using EPIMODEL. In: Francl L, Neher D (eds) Exercises in plant disease epidemiology. APS, St. Paul, pp 24-28

Orellana FJ, Del Sargado J, Del Águila IM (2011) SAIFA: a web-based system for integrated production of olive cultivation. Comput Electron Agric 78:231-237. doi:10.1016/j.compag.2011.07.014

Page L, Brin S, Motwani R, Winograd T (1998) The PageRank citation ranking: bringing order to the web. Technical report, Stanford University, Stanford, CA. Congress on Modeling and Simulation, Perth, Australia, 12-16 December 2011

Pajunen VI (1983) The use of physiological time in the analysis of insect stage-frequency data. Oikos 40:161-165

Parry HR, Aurambout JP, Kriticos DJ (2011) Having your cake and eating it: a modeling framework to combine processbased population dynamics and dispersal simulation. In: 19th international congress on modelling and simulation, Perth, Australia, 12-16 December

Patil SS, Dhandra BV, Angadi UB, Shankar AG, Joshi N (2009) Web based expert system for diagnosis of micronutrients' deficiencies in crops. In: Proceedings of the World Congress on Engineering and Computer Science 2009 Vol I WCECS 2009, October 20-22, 2009, San Francisco, USA, http://www.iaeng.org/publication/ WCECS2009/WCECS2009_pp266-268.pdf. Accessed 18 May 2015 
Pavan W, Fraisse CW, Peres NA (2010) Development of a web-based disease forecasting system for strawberries. Comput Electron Agric 75:169-175. doi:10.1016/j.compag.2010.10.013

Perini A, Susi A (2004) Developing a decision support system for integrated production in agriculture. Envir Mod Soft 19:821-829. doi: 10.1016/j.envsoft.2003.03.001 DOI:10.1016\%2Fj.envsoft.2003.03. 001

Phelps K, Collier RH, Reader RJ, Finch S (1993) Monte Carlo simulation method for forecasting the timing of pest insect attacks. Crop Prot 12:335-341. doi:10.1016/0261-2194(93)90075-T

Phelps K, Reader RJ, Hinde CJ (1999) HIPPO - flexible software for the construction, integration and distribution of biologically realistic models. Asp Appl Biol 55:81-88

Philomine R, Tauro CJM, Ganesan N (2012) Design and development of fuzzy expert system for integrated disease management in finger millets. IJCA 56:31-36. doi:10.5120/8857-2815

Plant RE, Mangel M (1987) Modeling and simulation in agricultural pest management. SIAM Rev 29:235-236. doi:10.1137/1029043

Plénet D, Giauque P, Navarro et al (2009) Using on-field data to develop the EFI information system to characterise agronomic productivity and labour efficiency in peach (Prunus persica L. Batsch) orchards in France. Agric Syst 100(1-3):1-10. doi:10.1016/j.agsy.2008.11. 002

Prasad GY, Prabhakar M (2012) In: Abrol DP, Shankar U (eds) Integrated pest management: principles and practice. $\mathrm{CAB}$ International

Prasad R, Ranjan KR, Sinha AK (2006) AMRAPALIKA: an expert system for the diagnosis of pests, diseases, disorders in Indian mango. KBS 19:9-21

Pruess KP (1983) Day-degree methods for pest management. Environ Entomol 12:613-619. doi:10.1093/ee/12.3.613

Rehman A, Shaikh ZA (2011) ONTAgri: scalable service oriented agriculture ontology for precision farming. ABE 1-2:411-413

Rousse P, Gourdon F, Roubaud M, Chiroleu F, Quilici S (2009) Biotic and abiotic factors affecting the flight activity of Fopius arisanus, an egg-pupal parasitoid of fruit fly pests. Environ Entomol 38:896-903

Saini HS, Kamal R, Sharman AN (1998) SOYPEST: an EXpert system for insect pest management in soybean crop. CSI Communications, April, pp 21-24

Saini HS, Kamal R, Sharma AN (2002) Web based fuzzy expert system for integrated pest management in soybean. Int J Inf Technol 8:5574

Samietz J, Graff B, Höhn H et al (2008) SOPRA: phenology modeling of major orchard pests - from biological basis to decision support. Acta Horticult 803:35-42

Seem R (2001) Plant disease forecasting in the era of information technology. In: Plant disease forecast: information technology in plant pathology. Kyongju, Republic of Korea

Sharpe PJH, Curry GL, DeMichele DW, Cole CL (1977) Distribution model of organism development times. J Theor Biol 66:21-38. doi:10.1016/0022-5193(77)90309-5

Singh U, Brink JE, Thornton PK, Christianson CB (1993) Linking crop models with geographic information system to assist decision making: a prototype for the Indian semiarid tropics. International Fertilizer Development Center, Muscle Shoals, Alabama, USA. Paper series - IFDC P-19.39 p

Sini M (2009) Semantic technologies at FAO. Agricultural information management standards, International Society for Knowledge Organization (ISKO), 3 April 2009

Siraj F, Nureize A (2006) Integrated pest management system using fuzzy expert system, In: Proceedings of knowledge management international conference \& exhibition (KMICE), Malaysia (2006), pp 169176

Soergel D, Lauser B, Liang A, Fisseha F, Keizer J, Katz S (2004) Reengineering thesauri for new applications: the AGROVOC example, J Dig Info vol. 4. http://www.fao.org/3/a-af234e.pdf. Accessed 18 May 2015
Sporelder M, Simon R, Gonzales JC et al (2009) Ilcm — insect life cycle modeling: a software package for developing temperature based insect phenology models with applications for regional and global risk assessments and mapping. International Potato Centre, Lima

Stephens AEA, Denter PR (2005) Thrips palmi-potential survival and population growth in New Zealand. N Z Plant Prot 58:24-30

Stern VM, Smith RF, van den Bosch R, Hagen KS (1959) The integrated control concept. Hilgardia 29:81-101. doi:10.3733/hilg. v29n02p081

Stone ND, Saarenma H (1988) Expert systems and IPM: an overview. 71-87. In: Cavalloro, R, Deluchi C (eds) Proceedings of the Parasitis 88 Congress, Spain. October 25-28, 1988.

Strand JF (2000) Some agrometeorological aspects of pest and disease management for the 21st century. Agric For Meteorol 103:73-82. doi:10.1016/S0168-1923(00)00119-2

Strickland RM, Ess DR, Parson SD (1998) Precision farming and precision pest management: the power of new crop production technologies. J Nematol 30:431-435

Sun J, Li S, Zhang L, Liu L, Zhao H, Yang J (2013) Ontology construction in tea pest domain. Linked data Knowl Graph 406:228-234

Sutherst RW, Maywald GF, Russell BL (1991) From CLIMEX to PESK $\mathrm{Y}$, a generic expert system for pest risk assessment. OEPP Bull 21: 595-608

Sutherst RW, Maywald GF, Yonow T, Stevens PM (1999) CLIMEX: predicting the effects of climate on plants and animals. CSIRO, Collingwood, $\mathrm{p} 88$

Taye MM (2010) Understanding semantic web and ontologies: theory and applications. J Comp 2:182-191

Teng PS (1985) A comparison of simulation approaches to epidemic modeling. Annu Rev Plant Physiol Plant Mol Biol 23:351-379. doi:10.1146/annurev.py.23.090185.002031

The Plant Ontology Consortium (2002) The Plant Ontology Consortium and plant ontologies. Comp Funct Genom 3:137-142. doi:10.1002/ cfg.154 DOI:10.1002\%2Fcfg.154\#pmc_ext

Tilman D (1999) Global environmental impacts of agricultural expansion: the need for sustainable and efficient practices. PNAS 96: 5995-6000. doi:10.1073/pnas.96.11.5995

Tilman D, Fargione J, Wolff B et al (2001) Forecasting agriculturally driven global environmental change. Science 292:281-284. doi: 10.1126/science. 1057544

Trnka M, Muska F, Semaradova D et al (2007) European corn borer life stage model: regional estimates of pest development and spatial distribution under present and future climate. Ecol Model 207:6184. doi:10.10165/j.ecolmodel.2007.04.014

Van den Bosh R, Stern VM (1969). The effect of harvesting practices on insect populations in alfalfa. In: Komarek R (ed) Proc. Tall Timbers Conf. on Ecol. Anim. Contr. Habitat Manag 1: 47-54

Van der Have TM (2008) Slaves to the Eyring equation?: temperature dependence of life-history characters in developing ectotherms. Dissertation, Department of Environmental Sciences, Resource Ecology Group, Wageningen University, The Netherlands, 2008.

Van Evert FK, Campbell GS (1994) Cropsyst - a collection of objectoriented simulation-models of agricultural systems. Agron J 86: 325-331. doi:10.2134/agronj1994.00021962008600020022x

Van Maanen A, Xu M (2003) Modeling plant disease epidemics. Eur J Plant Pathol 109:669-682

Visser U, Voges U, Streit U (1994). Integration of AI-, database- and telecommunication-techniques for the plant protection expert system PRO PLANT (1994). In: Industrial and engineering applications of artificial intelligence and expert systems, vol 7 of International Conference of IEA/AIE, 367-374. Gordon and Breach Science Publisher, NJ, 1994

Wagner TL, Wu HI, Sharpe PJH, Schoolfield RM, Coulson RN (1984a) Modelling insect development rates: a literature review application of a biophysical model. Ann Entomol Soc Am 77:208-225. doi:10. 1093/aesa/77.2.208 
Wagner TL, Wu HI, Sharpe PJH, Coulson RN (1984b) Modelling distributions of insect development time: a literature review and application of the Weibull function. Ann Entomol Soc Am 77:475-487. doi:10.1093/aesa/77.5.475

Wagner TL, Wu HI, Feldman RM, Sharpe PJH, Coulson RN (1985) Multiple-cohort approach for simulating development of insect populations under variable temperatures. Ann Entomol Soc Amer 78: 691-704. doi:10.1093/aesa/78.6.691

Waheed IB, Coop L, Kogan M (2003) Integrated pest management and internet-based delivery systems. Neotrop Entomol $32: 373-83$

Willocquet L, Savary S, Fernandez L et al (2002) Structure and validation of RICEPEST, a production situation-driven, crop growth model simulating rice yield response to multiple pest injuries for tropical Asia. Ecol Mod 153:247-268. doi:10. 1016/S0304-3800(02)00014-5

Xinxing L, Zhang L, Fu Z et al (2012) The corn disease remote diagnostic system in China. J Food Agric Environ 10:617-620
Xu X (2006) Modeling and interpreting disease progress in time. In: Cooke BM, Jones DG, Kayge B (eds) The epidemiology of plant diseases. Springer, Dordrecht, pp 215-238

Yelapure SJ, Kulkarni RV (2012) Literature review on expert system in agriculture. Int J Comp Sci Inf Tech 3:5086-5089

Youen J, Twengström E, Sigvald R (1996) Calibration and verification of risk algorithms using logistic regression. Eur J Plant Pathol 102:847-854

Zalom F, Strand J (1990) Alternatives to targeted pesticides: the DANR database. Calif Agric 44:16-20. doi:10.3733/ca.v044n04p16

Zhang S, Goddard S (2007) A software architecture and framework for web-based distributed decision support systems. DSS 43:11331150. doi:10.1016/j.dss.2005.06.001

Zhang W, Ricketts TH, Kremen C et al (2008) Ecosystem services and dis-services to agriculture. Ecol Econ 64:253-260. doi:10.1016/j. ecolecon.2007.02.024

Zheng Y, Qian P, Li Z (2012) Construction of the ontology-based agricultural knowledge management system. J Int Agric 11:700-709. doi:10.1016/S2095-3119(12)60059-8 